\title{
MANCHESTER
}

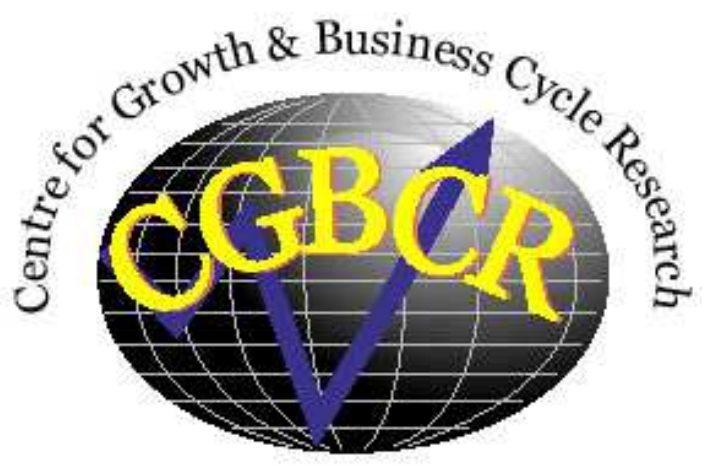

Discussion Paper Series

\section{Financial Regulation, Credit and Liquidity Policy and the Business Cycle \\ By}

\section{George J. Bratsiotis, William J. Tayler, Roy Zilberman}

Centre for Growth and Business Cycle Research, Economic Studies, University of Manchester, Manchester, M13 9PL, UK

October 2014

Number 196

Download paper from:

http://www.socialsciences.manchester.ac.uk/cgbcr/discussionpape rs/index.html 


\title{
Financial Regulation, Credit and Liquidity Policy and the Business Cycle
}

\author{
George J. Bratsiotis* William J. Tayler ${ }^{\dagger} \quad$ Roy Zilberman ${ }^{\ddagger} \S$ \\ Initial draft: December 1, 2012 \\ This version: October 29, 2014
}

\begin{abstract}
The global financial crisis in 2007 prompted policy makers to introduce a combination of bank regulation and macroprudential policies, including non-conventional monetary policies, such as interest on reserves and changes in required reserves. This paper examines how the combination of such policies can help stabilize the effects of real and financial shocks in economies where financial frictions are important. Although there is an extensive literature on financial regulation and macroprudiential policy, and more recently some literature on the effects of interest on reserves, these policies are usually examined independently. The results point to the importance of coordination between financial regulation and monetary policy in minimizing welfare losses following such shocks. Interest on reserves is shown to be more effective in reducing welfare losses than changes in required reserves and to play a significant role in making stabilization policy more effective. The results also suggest an easing of bank capital requirements during recessions, when output and loans are falling and the risk of default is high.
\end{abstract}

JEL Classification Numbers: E31, E32, E44, E52, E50, G28

Keywords: credit frictions; bank capital regulation; macroprudential policy; liquidity, interest on reserves; required reserves; risk of default; business cycle.

\footnotetext{
*Corresponding author: School of Social Sciences, Economics, University of Manchester, and Centre for Growth and Business Cycle Research, Manchester, United Kingdom, M13 9PL. Email: george.bratsiotis@manchester.ac.uk.

$\dagger$ Lancaster University Management School, Department of Economics, United Kingdom, LA14YX. E-Mail: w.tayler@lancaster.ac.uk.

${ }^{\ddagger}$ Lancaster University Management School, Department of Economics, United Kingdom, LA14YX. E-Mail: r.zilberman@lancaster.ac.uk.

$\S$ Acknowledgments: TBC.
} 


\section{Introduction}

The global financial crisis in 2007, that is claimed to have caused the deepest international recession since the Great Depression, called for a combination of new global financial regulation and non-conventional monetary policies that sought to improve the way that financial and credit markets and the real economy can be stabilised following shocks. Basel III (2010), tried to improve on the inflexibility of its predecessors (Basel I and II), by being stricter with bank capital requirements and the idiosyncratic risk of borrowers, while allowing for countercyclical capital buffers, to account for the state of the real economy, and seeking additional liquidity requirements. A small sample of an extensive literature that examines the effects of Basel III and bank regulation in general includes, Drumond (2009), Meh and Moran (2010), Covas and Fujita (2010), Dib (2010), Benes and Kumhof (2011), Aliaga-Diaz and Olivero (2012), Repullo and Suarez (2013), and Angelini et al (2014), among others.

Similarly, at the national level, central banks have been experimenting with nonconventional monetary policies that aim at macroprudential measures and liquidity management. One of the liquidity policies that has attracted much interest recently, is that on the interest offered on reserves held at the central bank. On October 6, 2008, the Federal Reserve Board, introduced interest payments on depository institutions' required and excess reserve balances. This was seen as an important policy step, as the Fed's various liquidity facilities, introduced during the financial crisis, were placing downward pressure on the Federal funds rate. It was believed that the interest on reserves would give the Fed "greater scope to use its lending programs to address conditions in credit markets while also maintaining the federal funds rate close to the target...". ${ }^{1}$ Indeed, following the introduction of interest payments on reserves, in 2008, (with the Fed paying an annual interest rate of $0.25 \%$ ), excess reserves increased dramatically. ${ }^{2}$ Similar policies have been adopted by the ECB, Bank of Japan, Bank of Canada and other central banks in recent years. ${ }^{3}$

As Ireland (2011) shows, interest on reserves (IOR), provides the monetary authority with "an additional degree of freedom that it can use to target the supply of reserves

\footnotetext{
${ }^{1}$ Board of Governors, Federal Reserve System, (October 6, 2008)

${ }^{2} \mathrm{Up}$ to that point required reserves in the US had been very close to total reserves, with excess reserves historically being less than $10 \%$ of total reserves.

${ }^{3}$ In the ECB, the IOR reached $0.25 \%$ in 2008 . However, as credit and liquidity markets remained very tight, and deflation was becoming a concern in the Eurozone, the ECB decided to reduce the interest rate on the deposit facility to zero (11 July 2012), and more recenly, (June 11, 2014), to a negative $-0.10 \%$, (along with a reduction of the refinance rate, by 10 basis points, to $0.15 \%$ ).
} 
to the banking system independently from the short-term market rate". Support of this is also suggested in Goodfriend (2002), Curdia and Woodford (2011), Dutkowskya and VanHoose (2011), Kashyap and Stein (2012). Much of this recent literature, however, does not examine whether the IOR can be an optimal policy instrument within a model where bank regulation, macroprudential monetary policy and required reserve policy are also simultaneously available and active, as implemented in many countries in recent years. Glocker and Towbin (2012), introduce excess and required reserves, with IOR offered on both, within the Bernanke, Gertler and Gilchrist (1999) framework. They show that when financial frictions are important, and when financial stability matters for welfare, the use of reserve requirements can lead to substantial welfare improvements. Their focus however, is on required reserves rather than the IOR; moreover, as with the bulk of the literature, their results are examined independently of bank regulation and macroprudential monetary policy. Conversely, the combination of bank regulation and macroprudential policy has recently been examined extensively, (see Angeloni and Faia 2010, Angelini, Neri and Panetta 2011, Benes and Kumhof 2011, Angelini et al, 2014), but this literature does not usually address the role of liquidity policy, particularly with respect to IOR or required reserves.

In this paper we use a different framework to Bernanke, Gertler and Gilchrist (1999), that provides us with more flexibility to examine the combination of bank regulation and macroprudential monetary policy, including interest on reserves and minimum required reserves, simultaneously. In particular, we use a DSGE model with sticky prices and wages, that incorporates the cost channel effect the balance sheet effect, the financial accelerator effect, and an endogenous probability of firm default that leads to a countercyclical finance premium, (as in Agénor, Bratsiotis and Pfajfar, 2012). The borrowing cost channel in this model, contributes to the standard monetary policy cost channel, (i.e. Christiano, Eichenbaum and Evans 2005, Ravenna and Walsh 2006), by introducing more financial frictions and a richer banking environment. Within this framework, financial regulation takes place in the form of bank capital requirements, the macroprudential monetary policy is represented by an augmented Taylor-rule that also accounts for credit volatility and risk, and liquidity policy is determined by policy on required reserves and interest on reserves, (IOR). Welfare is measured in terms of inflation and the output gap (as in Kannan, Rabanal and Scott, 2012, Glocker and Towbin 2012, Angelini, Neri and Panetta, 2014, among many others), but we also consider two welfare loss functions that account for financial stability.

The results suggest that policy coordination between the financial regulation and mon- 
etary authorities is crucial for minimising welfare loss following real and financial shocks. We also find that bank capital requirements should be lower during recessions, when output and loans are falling and the risk of default is already high. This is not inconsistent with some other studies that support countercyclical bank capital buffers, as proposed in Basel III, (see Benes and Kumhof, 2011, Darracq-Paries, Sørensen, Rodriguez-Palenquela, 2011, Repullo and Suarez 2013, Angelini et al, 2014). The results also show that real and financial stability, but also welfare, can all be substantially improved when, in conjunction with bank regulation and macroprudential monetary policy, the monetary authority also uses IOR to stabilise the economy. Key to this result is the fact that IOR can affect directly the deposit rate and hence the level of excess reserves and liquidity, allowing the policy rate more flexibility to target inflation. This provides the central bank with an extra degree of freedom to control liquidity while stabilise more effectively the real economy and the financial markets. This result is consistent with the findings of Ireland (2011) who, in a very different framework to this model, reaches the same conclusion, but also shows that IOR affects deposits and the monetary base without directly affecting the long-run market rate. ${ }^{4}$

The remaining of the paper is structured as follows. Section 2 develops the main macro model, including the financial contract between firms and the bank. Section 3 describes the financial regulation and the macroprudential monetary and liquidity policies. Section 4 completes the aggregate model. Section 5 explains the steady state and the parameterisation of the model. Section 6 describes the welfare analysis and explains the dynamic behaviour of the model following three different types of shocks: technology, policy and bank capital shocks; section 7 concludes.

\section{The Model}

The economy consists of many differentiated labor type $i \in(0,1)$ households, a competitive labour contractor, many differentiated intermediate goods firms $j \in(0,1)$, a competitive final good firm, a representative competitive bank, a central bank (that is also in charge of financial regulation) and a government. The intermediate goods firms combine capital and labour services, which they rent from households, to produce a differentiated intermediate good. Capital required by intermediate goods firms in period $t$

\footnotetext{
${ }^{4}$ Ireland (2011) does not examine credit frictions or bank regulation, but focuses on the effects of IOR on the monetary base, which in this paper we do not model explicitly as it is not the main focus of our paper.
} 
is available to households in period $t-1 .^{5}$ The final good firm combines the intermediate goods for producing a competitive final good.

Unlike the bulk of the literature, where the risk is confined to risky capital investors, the risk in this model comes from goods producing firms who borrow funds from the bank to cover their working capital needs (labour and capital), but their production is subject to an idiosyncratic shock, (i.e. Agénor, Bratsiotis and Pfajfar 2012, Fiore and Tristani 2013). ${ }^{6}$ The latter makes their loan repayment risky and so firms must pledge a fraction of their output as collateral in case of default. There is a full transmission of risk from firms to the bank. The bank's funds are made of deposits and equity (bank capital). Bank equity offers a higher return than deposits because of the risk it carries if the bank, which is exposed to firms' risk, defaults. Otherwise, the return on bank equity is determined by the consumption-equity investment choice of households, taking as given the supply of equity, where the latter is determined by regulatory requirements (as set by the Basel Conventions). The loan rate is set by the bank as a finance premium over the risk-free deposit rate and it is endogenously derived based on the distribution of the idiosyncratic risk of the firm. If the firm defaults, the bank uses the firm's pledged collateral to pay back depositors and then lets bank equity holders absorb the rest of the cost of default. The regulatory requirements are supervised by the central bank, which can also request from the government to levy a financial tax, if extra liquidity is required to cover deposit holders in the case of a bank default. Thus, although deposits are safe, bank equity has a probability of default which is linked to the firm's default probability. Financial regulation and monetary policy rules, responding to risk (probability of firm default), equity (bank capital) and liquidity (credit, required reserves and interest on reserves), and their implications for welfare, are also examined.

\subsection{Households}

Each household $i$, maximises ${ }^{7}$

$$
U_{i, t+s}=\mathbb{E}_{t} \sum_{s=0}^{\infty} \beta^{s}\left(\frac{\sigma}{\sigma-1} c_{t+s}^{(\sigma-1) / \sigma}-\frac{h_{i, t+s}^{1+\eta}}{1+\eta}\right),
$$

\footnotetext{
${ }^{5}$ This is based on the assumption that capital takes time to build. As with all such models, the production of bank capital takes place implicitly within the productions of all goods.

${ }^{6}$ In Fiore and Tristani (2013) entrepreneurs own firms producing a homogeneous good in the wholesale sector and, in general, their model framework and focus is different to ours.

${ }^{7}$ Note that capital Latin letters (i.e. $X_{t}$ ) denote nominal variables, whereas small letters, (i.e. $x$ ) denote real variables. Exceptions are the inflation rate $\pi_{t}$ and real profits, $\Pi_{t}$. Hats, $\widehat{X}$, denote loglinearised deviations of variables from their steady states.
} 
where $\sigma>0$, is the intertemporal elasticity of substitution in consumption, $\eta$ is the inverse of the Frisch elasticity of labour supply, $\mathbb{E}_{t}$ the expectations operator and $\beta \in(0,1)$, is the discount factor. Households ultimately own everything: firms, physical capital and the bank. They supply $h_{i, t}$ of labor hours to firms at a nominal wage rate $W_{i, t}$ and provide capital services, $\bar{k}_{t}=u_{t} k_{t-1}$, to firms at the rental price of $r_{t}^{k}$, where $u_{t}$ is capital utilisation. Capital depreciates at the rate, $\delta_{0} u_{t}^{\delta_{1}}$, and so it is a function of the intensity of capitalisation. Furthermore, the cost capital utilisation is a function of the intensity of use of capital, $\delta_{0} u_{t}^{\delta_{1}} k_{t-1}$. Each household chooses consumption $\left(c_{t}\right)$, investment $\left(i_{t}\right)$, capital utilisation $\left(u_{t}\right)$, real deposits $\left(d_{t}\right)$, and real bank equity $\left(e_{t}\right)$ to maximize expected discounted utility, (1), subject to,

$$
\begin{gathered}
c_{t}+i_{t}+d_{t}+e_{t} \leq \frac{R_{t-1}^{d} d_{t-1}}{\pi_{t}}+\left(1-\Phi_{t-1}^{B}\right) \frac{R_{t-1}^{e} e_{t-1}}{\pi_{t}}+\left(1+\tau_{t}^{w}\right) \frac{W_{i, t}}{P_{t}} h_{i, t}+ \\
r_{t}^{k} \bar{k}_{t}+\Pi_{t}-\tau_{t}-\frac{\xi_{E}}{2}\left(\frac{e_{t}}{e_{t-1}}-1\right)^{2} e_{t}
\end{gathered}
$$

and the dynamic evolution of capital,

$$
k_{t}=\left(1-\delta_{0} u_{t}^{\delta_{1}}\right) k_{t-1}+\left(1-\frac{\xi_{k}}{2}\left(\frac{i_{t}}{i_{t-1}}-1\right)^{2}\right) i_{t}
$$

where, $\pi_{t}^{P} \equiv P_{t} / P_{t-1}$, is defined as the gross rate of price inflation, with $P_{t}$ denoting the price of the final good. The terms $R_{t}^{d}$ and $R_{t}^{e}$, are the gross nominal returns to deposit and equity holders respectively, while $\Phi_{t}^{B}$ is the probability of bank default, derived below. If the bank collapses in the previous period, (i.e. $\Phi_{t-1}^{B}=1$ ), then equity holders must absorb any incurred financial losses. The expression $\left(1+\tau_{t}^{w}\right)$, is the familiar subsidy to offset inefficiencies due to the wage setting. $\Pi_{t}$ is the sum of real profits by firms and deposit and lending banks accruing to the household. $\tau_{t}$ is an emergency liquidity lump tax that the government can raise in times of shortfalls of liquidity to refund depositors. The last term in (2) comes from the assumption that bank capital across periods involves some quadratic adjustment cost. ${ }^{8}$ Similarly, the term $\xi_{k}$ determines the size of any capital adjustment costs. All households have identical initial endowments and portfolio preferences. ${ }^{9}$

\footnotetext{
${ }^{8}$ Note that although loan contracts are re-negiotiated at the beginning of every period, bank capital is tradable (see Christiano, Motto and Rostagno 2010). In addition, in this paper, bank capital is subject to some broker and adjustment costs, though these are not crucial for our results, as we show below.

${ }^{9}$ All households are identical and work the same individual quantity of hours. Thus, the $i$ index is dropped from all variables other than labour services. In addition, the structure of the labour markets employed here rules out labour income differentials, (see also Christiano, Motto and Rostagno 2010).
} 


\subsubsection{Consumption and Wealth Allocation Decisions}

From the maximisation problem, (1)-(2), we obtain the following first order conditions,

$$
\begin{aligned}
\partial c_{t}: & c_{t}^{-\frac{1}{\sigma}}=\lambda_{t}^{c}, \\
\partial d_{t}: & \mathbb{E}_{t}\left(\frac{\beta \lambda_{t+1}^{c} R_{t}^{d}}{\pi_{t+1}}\right)=\lambda_{t}^{c}, \\
\partial e_{t}: & \lambda_{t}^{c}\left[1+\xi_{e}\left(\frac{e_{t}}{e_{t-1}}-1\right) \frac{e_{t}}{e_{t-1}}+\frac{\xi_{e}}{2}\left(\frac{e_{t}}{e_{t-1}}-1\right)^{2}\right] \\
= & \beta \mathbb{E}_{t} \lambda_{t+1}^{c}\left[\xi_{e}\left(\frac{e_{t+1}}{e_{t}}-1\right)\left(\frac{e_{t+1}}{e_{t}}\right)^{2}+\frac{\left(1-\Phi_{t-1}^{B}\right) R_{t}^{e}}{\pi_{t+1}^{P}}\right], \\
\partial u_{t}: & \frac{\lambda_{t}^{c}}{\lambda_{t}^{k}} r_{t}^{k}=\delta_{0} \delta_{1} u_{t}^{\delta_{1}-1}, \\
\partial k_{t}: & \lambda_{t}^{k}=\beta \mathbb{E}_{t}\left[\lambda_{t+1}^{c} r_{t+1}^{k} u_{t+1}+\lambda_{t+1}^{k}\left(1-\delta_{0} u_{t+1}^{\delta_{1}}\right)\right], \\
\partial i_{t}: & T Q^{-1} \equiv \frac{\lambda_{t}^{c}}{\lambda_{t}^{k}}=\left[1-\frac{\xi_{k}}{2}\left(\frac{i_{t}}{i_{t-1}}-1\right) \frac{i_{t}}{i_{t-1}}-\frac{\xi_{k}}{2}\left(\frac{i_{t}}{i_{t-1}}-1\right)^{2}\right] \\
& +\beta \mathbb{E}_{t}\left[\xi_{k}\left(\frac{i_{t+1}}{i_{t}}-1\right) \frac{i_{t+1}^{2}}{i_{t}^{2}} \frac{\lambda_{t+1}^{k}}{\lambda_{t}^{k}}\right],
\end{aligned}
$$

where $\lambda_{t}^{c}$ and $\lambda_{t}^{k}$ are the respective Lagrange multipliers and $T Q \equiv \lambda_{t}^{k} / \lambda_{t}^{c}$ is the price that defines the relationship between the cost of capital and the adjustment costs of capital (Tobin's q).

From equations (4) and (5) we obtain the Euler equation,

$$
c_{t}^{-\frac{1}{\sigma}}=\mathbb{E}_{t}\left(\frac{\beta R_{t}^{d}}{\pi_{t+1}} c_{t+1}^{-\frac{1}{\sigma}}\right)
$$

Combining equations (5) and (6) yields the the arbitrage-free condition between the return on bank capital and the risk free deposit rate,

$$
\begin{aligned}
R_{t}^{e}= & \frac{R_{t}^{d}}{1-\Phi_{t}^{B}}\left[1+\xi_{e}\left(\frac{e_{t}}{e_{t-1}}-1\right) \frac{e_{t}}{e_{t-1}}+\frac{\xi_{e}}{2}\left(\frac{e_{t}}{e_{t-1}}-1\right)^{2}\right] \\
& -\frac{\xi_{e}}{1-\Phi_{t}^{B}} \mathbb{E}_{t}\left[\pi_{t+1}\left(\frac{e_{t+1}}{e_{t}}-1\right)\left(\frac{e_{t+1}}{e_{t}}\right)^{2}\right]
\end{aligned}
$$

Thus, even in the absence of bank equity adjustment costs, $\xi_{e}=0$, the return on bank capital is higher than the risk-free deposit rate due to the probability of bank default. This is also true in the long run because, as we show below, at the steady state, $\Phi^{B}>0$, hence $R^{e}=R^{d} /\left(1-\Phi^{B}\right)>R^{d}$. 


\subsubsection{Wage Setting, Labour Demand and Wage Inflation}

The wage setting follows a variant of Erceg, Henderson and Levin, (2000), where each household $i$ supplies $h_{i, t}$ hours of a unique type of labour, but all types of labour hours are aggregated by a competitive labour contractor into a composite homogenous labour as required in production, ${ }^{10}$

$$
n_{t}=\left(\int_{0}^{1} h_{i, t}^{\frac{\lambda_{w}-1}{\lambda w}} d i\right)^{\frac{\lambda_{w}}{\lambda_{w}-1}}
$$

where $\lambda_{w}>1$. The $i^{t h}$ household, therefore, faces the following demand curve for its labour,

$$
h_{i, t}=\left(\frac{W_{i, t}}{W_{t}}\right)^{-\lambda_{w}} n_{t},
$$

where $W_{t}$ denotes the aggregate nominal wage index paid for one unit of composite labour, $W_{t}=\left[\int_{0}^{1} W_{i, t}^{1-\lambda_{w}} d i\right]^{\frac{1}{1-\lambda w}}$. In each period a constant fraction, $1-\omega_{w}$, of workers are able to re-optimize their wages while a fraction of $\omega_{w}$ index their wages according to last period's inflation rate, $W_{i, t}=\pi_{t-1} W_{i, t-1}$. The average wage at period $t$ is therefore, $W_{t}^{1-\lambda_{w}}=\omega_{w}\left(\pi_{t-1} W_{t-1}\right)^{1-\lambda_{w}}+\left(1-\omega_{w}\right)\left(W_{t}^{*}\right)^{1-\lambda_{w}}$. From (1) and the above problem, wage inflation is,

$$
\hat{\pi}_{t}^{W}=\beta \mathbb{E}_{t} \hat{\pi}_{t+1}^{W}+\frac{\left(1-\omega_{w}\right)\left(1-\beta \omega_{w}\right)}{\left(\omega_{w}\right)\left(1+\eta \lambda_{w}\right)}\left(\widehat{m r}_{t}-\hat{w}_{t}\right),
$$

where, $\widehat{m r} s_{t}=\eta \widehat{n}_{t}+\frac{1}{\sigma} \widehat{c}_{t}$, and the log-linearised real wage evolves according to,

$$
\hat{w}_{t} \equiv \hat{w}_{t-1}+\hat{\pi}_{t}^{W}-\hat{\pi}_{t}^{P}
$$

where $\hat{\pi}_{t}^{P} \equiv \hat{P}_{t}-\hat{P}_{t-1}$.

\subsection{The Final Goods Firm}

The competitive final good firm assembles all intermediate goods $y_{j, t}, j \in(0,1)$, to produce a final output, $y_{t}$, which then sells at the price $P_{t}$. The composite good, $y_{t}$, is produced based on a CES technology with Dixit-Stiglitz preferences,

$$
y_{t}=\left(\int_{0}^{1} y_{j, t}^{\frac{\lambda_{p}-1}{\lambda_{p}}} d j\right)^{\frac{\lambda_{p}}{\lambda_{p}-1}}
$$

\footnotetext{
${ }^{10}$ See also Christiano, Eichenbaum and Evans (2005) and Smets and Wouters (2002).
} 
where $\lambda_{p}>1$, denotes the constant elasticity of substitution between the differentiated intermediate goods. The demand for each intermediate good $j$ is,

$$
y_{j, t}=y_{t}\left(\frac{P_{j, t}}{P_{t}}\right)^{-\lambda_{p}},
$$

where the price $P_{j, t}$, is set by intermediate firms and the average price index is,

$$
P_{t}=\left(\int_{0}^{1} P_{j, t}^{1-\lambda_{p}} d j\right)^{\frac{1}{1-\lambda_{p}}}
$$

\subsection{Intermediate Goods Entrepreneur - Firms}

There is a continuum of firms $j \in(0,1)$, each producing a differentiated good that is sold as an intermediate good into the production of the final good $y_{t}$. Firms borrow money from the bank to cover their labour and capital costs. Each firm decides on its required levels of labour and capital, but also the selling price of its good, $P_{j, t}$, by taking as given the loan rate set by the lending bank at the beginning of each period. In this model firms play a key role, as they are the entrepreneurs whose production is subject to an idiosyncratic shock.

\subsubsection{Production: Default Risk and Borrowing}

The production of each firm $j$ is,

$$
y_{j, t}=z_{j, t} \bar{k}_{j, t}^{\alpha} n_{j, t}^{1-\alpha}
$$

where $n_{j, t}$ is the amount of homogenous composite labour employed by firm $j$. The term $\bar{k}_{t}=u_{t} k_{t-1}$, is capital services rented from households and $z_{j, t}$ captures the total productivity shock experienced by each firm $j$. The latter is subject to both economy-wide technology shocks, $\epsilon_{t}^{z}$ and an idiosyncratic shock, $\varepsilon_{j, t}$,

$$
z_{j, t}=\varepsilon_{j, t} \epsilon_{t}^{z}
$$

The economy wide technology shock, $\left(\epsilon_{t}^{z}\right)$ follows an $A R(1)$ process and has a mean, $\epsilon^{z}=1$. The idiosyncratic shock, $\varepsilon_{j, t}$, is uniformly distributed over the interval $(\underline{\varepsilon}, \bar{\varepsilon})$, with a constant variance and a mean value of unity. ${ }^{11}$ Each firm borrows to cover all its

\footnotetext{
${ }^{11}$ With no loss in generality, we assume that at the aggregate levels, idiosyncratic shocks are also unity and driven by aggregate shocks, as employed elsewhere in the literature, thus, $z_{t}=\epsilon_{t}^{z}$, (see also, Agénor, Bratsiotis and Pfajfar 2012, and Fiore and Tristani 2013).
} 
working capital needs, so its required borrowing (in real terms) is,

$$
l_{j, t}=r_{t}^{k} \bar{k}_{j, t}+w_{t} n_{j, t} .
$$

Thus all firms' funding is external. ${ }^{12}$ In times of good states, firms repay their lenders the full borrowing cost, $R_{t}^{l} l_{j, t}=R_{t}^{l}\left(r_{t}^{k} \bar{k}_{j, t}+w_{t} n_{j, t}\right)$, where $R_{t}^{l}$ is the gross loan rate, as set in the financial contract between the bank and the firm (derived below). As production is risky, borrowing requires some collateral that the firm can pledge in the event of default. It is assumed that in the latter case, the lender seizes a fraction $\chi$ of the firm's output as collateral, as in Agénor, Bratsiotis and Pfajfar (2012). Consequently, default occurs when the real value of collateral is less than the amount that needs to be repaid to the bank at the end of the period,

$$
\chi y_{j, t}<R_{t}^{l} l_{j, t} .
$$

Let $\varepsilon_{j, t}^{m}$ be the cut-off value below which the firm defaults. Using equations (19) and (20), the cut-off condition can be defined as,

$$
\chi_{t} \epsilon_{t}^{z} \varepsilon_{j, t}^{m} \bar{k}_{j, t}^{\alpha} n_{j, t}^{1-\alpha}=R_{t}^{l} l_{j, t},
$$

from which we can derive the cut-off point of the firm,

$$
\varepsilon_{j, t}^{m}=\frac{R_{t}^{l} l_{j, t}}{\chi_{t} \epsilon_{t}^{z} \bar{k}_{j, t}^{\alpha} n_{j, t}^{1-\alpha}} .
$$

Thus, the cut-off value, $\varepsilon_{j, t}^{m}$, that is the maximum value below which the firm is forced to default, is a function of the size of the loan $\left(l_{j, t}\right)$, the cost of borrowing $\left(R_{t}^{l}\right)$, and the size of the collateral seized in case of default $\left(\chi_{t} \epsilon_{t}^{z} \bar{k}_{j, t}^{\alpha} n_{j, t}^{1-\alpha}\right)$, all of which are subject to random disturbances. Note that unlike the bulk of the related literature, the loan rate and thus the cut-off point, are shown below to be also endogenously determined by the bank equity rate, the equity-to-loan ratio (financial regulation) and all the monetary policy parameters in the model.

\subsubsection{Marginal Cost and Price Setting}

Price setting is based on Calvo-type contracts, where a portion $\omega_{p}$ of firms keep their prices fixed, while the rest, $1-\omega_{p}$, adjust prices optimally by taking the loan rate, set in the beginning of each period, as given. The firm maximises the expected discounted

\footnotetext{
${ }^{12}$ This is mainly because we are interested in economies with substantial credit frictions, but also for simplicity.
} 
value of current and future real profits,

$$
\max _{P_{j, t+s}} \mathbb{E}_{t} \sum_{s=0}^{\infty} \omega_{p}^{s} \beta^{s} \lambda_{t+s}\left(\frac{P_{j, t+s}}{P_{t+s}} y_{j, t+s}-m c_{j, t+s} y_{j, t+s}\right),
$$

subject to the demand for its good, (17). From the first order condition of the firm's problem, and using the information above, we derive the New Keynesian Phillips Curve,

$$
\hat{\pi}_{t}^{P}=\beta \mathbb{E}_{t} \hat{\pi}_{t+1}^{P}+\frac{\left(1-\omega_{p}\right)\left(1-\omega_{p} \beta\right)}{\omega_{p}} \widehat{m c}_{t}
$$

where,

$$
\widehat{m c}_{t}=\hat{\imath}_{t}^{l}+(1-\alpha) \hat{w}_{t}+\alpha \hat{r}_{t}^{k}-\hat{z}_{t}
$$

As shown from (26), (27), and (35) below, the cost channel effect in this model is endogenously determined, through the loan rate, by the policy and equity rates, financial regulation and all monetary policy parameters in the model. Thus, the borrowing cost channel in this model, contributes to the monetary policy cost channel described in Ravenna and Walsh (2006) and Christiano, Eichenbaum and Evans (2005), by introducing more financial frictions that arise from a richer banking environment.

\subsection{The Banking Sector}

The banking sector consists of a representative competitive bank with two branch banks: a deposit bank and a lending bank.

\subsubsection{The Deposit Bank}

The representative deposit bank receives deposits from all households. It keeps a fraction $\mu_{t}$ of its total deposits at the central bank, where it receives a gross rate of $R_{t}^{\mu}$ and makes the rest of its deposits, $\left(1-\mu_{t}\right) d_{t}$, available to the lending bank at the gross interbank rate $R_{t}^{c b}$. The interbank rate, $\left(R_{t}^{c b}\right)$, the required reserve ratio $\left(\mu_{t}^{c b}\right)$ and the interest rate facility on required and excess reserves (IOR), $R_{t}^{\mu}$, are set by the central bank and are considered as policy instruments. The deposit bank's maximisation problem is,

$$
\begin{aligned}
& \max _{R_{t}^{d}, \mu_{t}} \Pi_{t}^{d e p}=\mu_{t} R_{t}^{\mu} d_{t}+\left(1-\mu_{t}\right) R_{t}^{c b} d_{t}-R_{t}^{d} d_{t}-G_{t}^{\mu}(\cdot), \\
& \text { s.t. } \quad G_{t}^{\mu}=\psi_{1}\left(\mu_{t}-\mu_{t}^{c b}\right)+\frac{\psi_{2}}{2}\left(\mu_{t}-\mu_{t}^{c b}\right)^{2},
\end{aligned}
$$


where the cost of holding reserves is captured by a convex function, $G_{t}^{\mu}(\cdot)$, as in Glocker and Towbin, (2012). The above problem results in the following equilibrium deposit rate,

$$
R_{t}^{d}=R_{t}^{c b}-\mu_{t}\left(R_{t}^{c b}-R_{t}^{\mu}\right)-G_{t}^{\mu}
$$

where the policy-required reserve spread is $R_{t}-R_{t}^{\mu} \geq 0$, and excess reserves are:

$$
\mu_{t}-\mu_{t}^{c b}=-\frac{\psi_{1}}{\psi_{2}}-\frac{\left(R_{t}^{c b}-R_{t}^{\mu}\right)}{\psi_{2}} ; \quad \psi_{1}<0 \quad \text { and } \quad \psi_{2}>0
$$

With a competitive banking sector, when $\mu_{t}=0$, then from (28), the deposit rate must equal the refinance rate, $R_{t}^{d}=R_{t}^{c b}$. However, with a liquidity reserve requirement policy in place, $\left(\mu_{t}^{c b}>0\right)$, the deposit rate is affected by the opportunity cost of holding reserves.

\subsubsection{The Lending Bank}

The representative lending bank raises $\left(1-\mu_{t}\right) d_{t}$ funds via the deposit bank at the interbank gross rate, $R_{t}^{c b}$ and also issues regulatory bank capital, $e_{t}$ at the gross rate $R_{t}^{e}$. All funds are used to finance the working capital needs of the firms and thus are liabilities of the bank to households. The bank's balance sheet in real terms is,

$$
l_{t}=\left(1-\mu_{t}\right) d_{t}+e_{t}
$$

Raising funds through equity, than deposits, is more costly for the bank (since $R_{t}^{e}>R_{t}^{c b}$ ), and thus equity is issued by the bank only to satisfy bank capital regulatory requirements. However, the equity-loan ratio can fall below its legislative requirements due to a financial shock, as discussed in more detail below.

The Financial Contract and the Lending Rate The lending rate is set at the beginning of the period, before firms engage in their production activity and prior to their labour demand and pricing decisions. Firms may default on their loans at the end of the period due to random shocks. The contractual repayment to the commercial bank is uncertain and thus a legal collateral commitment forms part of the financial contract (see Agénor, Bratsiotis and Pfajfar 2012). Given a competitive environment, it is assumed that, on average, the bank wants to break-even, such that the expected income from lending to firms is equal to the total costs of borrowing these funds (deposits and bank equity) from households. The bank's expected (period) zero profit condition from lending 
to firm $j$ is,

$$
\int_{\varepsilon_{j, t}^{m}}^{\bar{\varepsilon}} R_{t}^{l} l_{j, t} f\left(\varepsilon_{j, t}\right) d \varepsilon_{j, t}+\int_{\underline{\varepsilon}}^{\varepsilon_{j, t}^{m}} \chi_{t} Y_{j, t} f\left(\varepsilon_{j, t}\right) d \varepsilon_{j, t}=\left(1-\mu_{t}\right) d_{t} R_{t}^{c b}+R_{t}^{e} e_{t}+\varphi(\cdot) e_{t},
$$

where $f\left(\varepsilon_{j, t}\right)$ is the probability density function of $\varepsilon_{j, t}$. The first element on the left hand side is the expected repayment to the bank in the non-default states while the second element is the expected return to the bank in the default states. The terms $\left(1-\mu_{t}\right) d_{t} R_{t}^{c b}$ and $R_{t}^{e} e_{t}$ are the cost of funds from deposits and and bank capital, respectively, whereas $\varphi(\cdot) e_{t}$ denotes a penalty cost (proportional to equity held) incurred when the bank equity-to-loan ratio falls below the minimum adequacy ratio determined by regulatory requirements. It is assumed that $\varphi(\cdot) e_{t}=\varphi_{0}\left(\frac{\gamma_{t}^{r e g}}{\gamma_{t}}\right)^{\varphi_{\gamma}} e_{t}$, where $\varphi_{0}>0$, $\gamma_{t}=e_{t} / l_{t}$ and $\gamma_{t}^{r e g}$ is the regulatory requirement ratio (defined in the next section). ${ }^{13}$ To derive the lending rate we use equation (28) and write equation (31) as,

$$
R_{t}^{l} l_{j, t}-\int_{\underline{\varepsilon}}^{\varepsilon_{j, t}^{m}}\left(R_{t}^{l} l_{j, t}-\chi_{t} Y_{j, t}\right) f\left(\varepsilon_{j, t}\right) d \varepsilon_{j, t}=\left(1-\mu_{t}\right) d_{t} R_{t}^{c b}+R_{t}^{e} e_{t}+\varphi_{0}\left(\frac{\gamma_{t}^{r e g}}{\gamma_{t}}\right)^{\varphi_{\gamma}} e_{t}
$$

Substituting (23) for $\chi_{t}\left(\epsilon_{t}^{z} \varepsilon_{j, t}^{m}\right) \bar{k}_{j, t}^{\alpha} n_{j, t}^{1-\alpha}=R_{t}^{l} l_{j, t}$ and using the production function (19), the above equation reduces to,

$$
R_{t}^{l} l_{j, t}-\int_{\underline{\varepsilon}}^{\varepsilon_{j, t}^{m}}\left(\varepsilon_{j, t}^{m}-\varepsilon_{j, t}\right) \chi_{t} z_{t} \bar{k}_{j, t}^{\alpha} n_{j, t}^{1-\alpha} f\left(\varepsilon_{j, t}\right) d \varepsilon_{j, t}=\left(1-\mu_{t}\right) d_{t} R_{t}^{c b}+R_{t}^{e} e_{t}+\varphi_{0}\left(\frac{\gamma_{t}^{r e g}}{\gamma_{t}}\right)^{\varphi_{\gamma}} e_{t}
$$

and using from the balance sheet, (30), the fact that, $d_{t}=\frac{l_{t}\left(1-\gamma_{t}\right)}{\left(1-\mu_{t}\right)}$, we can write,

$$
R_{t}^{l} l_{j, t}-\int_{\underline{\varepsilon}}^{\varepsilon_{j, t}^{m}}\left(\varepsilon_{j, t}^{m}-\varepsilon_{j, t}\right) \chi_{t} z_{t} \bar{k}_{j, t}^{\alpha} n_{j, t}^{1-\alpha} f\left(\varepsilon_{j, t}\right) d \varepsilon_{j, t}=l_{t}\left(1-\gamma_{t}\right) R_{t}^{c b}+R_{t}^{e} e_{t}+\varphi_{0}\left(\frac{\gamma_{t}^{r e g}}{\gamma_{t}}\right)^{\varphi_{\gamma}} e_{t} .
$$

To find an explicit expression for the probability of default, we use the distribution properties of the idiosyncratic shock: $\varepsilon_{t}$ is assumed to follow a uniform distribution over the interval $(\underline{\varepsilon}, \bar{\varepsilon})$; therefore, its probability density is $1 /(\bar{\varepsilon}-\underline{\varepsilon})$ and its mean $\mu_{\varepsilon}=(\bar{\varepsilon}+\underline{\varepsilon}) / 2$. Using this information and dividing $(34)$ by $l_{j, t}$, results, at the symmetric equilibrium, in

\footnotetext{
${ }^{13}$ Gerali, Neri, Sessa and Signoretti (2010) and Angelini and Gerali (2011) use a quadratic penalty in deviation from the regulatory requirement. However, in their models, increasing bank capital above the target level is penalized just as much as falling below the minimum level. Our specification implies that only a fall in equity below the required minimum ratio is penalized, whereas excess bank capital can lower perceived risk. This is consistent with the idea that bank capital buffers can mitigate financial risk.
} 
the following loan rate ${ }^{14}$

$$
R_{t}^{l}=\left(1-\gamma_{t}\right) R_{t}^{c b}+\gamma_{t} R_{t}^{e}+\varphi_{0}\left(\frac{\gamma_{t}^{r e g}}{\gamma_{t}}\right)^{\varphi_{\gamma}} \gamma_{t}+\frac{\chi_{t} \epsilon_{t}^{z} \bar{k}_{t}^{\alpha} n_{t}^{1-\alpha}}{l_{t}}\left(\frac{\bar{\varepsilon}-\underline{\varepsilon}}{2}\right) \Phi_{t}^{2},
$$

or in terms of the loan spread,

$$
R_{t}^{l}-R_{t}^{c b}=\gamma_{t}\left(R_{t}^{e}-R_{t}^{c b}\right)+\varphi_{0}\left(\frac{\gamma_{t}^{r e g}}{\gamma_{t}}\right)^{\varphi_{\gamma}} \gamma_{t}+\frac{\chi_{t} \epsilon_{t}^{z} \bar{k}_{t}^{\alpha} n_{t}^{1-\alpha}}{l_{t}}\left(\frac{\bar{\varepsilon}-\underline{\varepsilon}}{2}\right) \Phi_{t}^{2}
$$

where the probability of default is,

$$
\Phi_{t}=\int_{\underline{\varepsilon}}^{\varepsilon_{t}^{m}} f\left(\varepsilon_{t}\right) d \varepsilon_{t}=\frac{\varepsilon_{t}^{m}-\underline{\varepsilon}}{\bar{\varepsilon}-\underline{\varepsilon}}
$$

Equations 36-37, show that for any given bank capital-to-loan ratio $\left(\gamma_{t}\right)$ the loan rate differential $\left(R_{t}^{l}-R_{t}^{c b}\right)$ increases: (i) the higher is the bank-equity spread $\left(R_{t}^{e}-R_{t}^{c b}\right)$; (ii) the weaker is the bank's equity position in the credit markets. Conversely, if the bank capital-loan ratio $\gamma_{t}$ exceeds the regulatory minimum $\gamma_{t}^{r e g}$, then loan rate falls as an indication of less perceived risk; (iii) the higher is the finance-premium (final term in 36) that is a function of the probability of default $\left(\Phi_{t}\right)$ and the collateral pledged by the firm in relation to the actual size of borrowing, $\chi_{t} \epsilon_{t}^{z} \bar{k}_{t}^{\alpha} n_{t}^{1-\alpha} / l_{t}$, (which can be thought of as the current sizeable net worth value of the firm in relation the size of loans). The probability of default $\left(\Phi_{t}\right)$ is determined by the cut-off point beyond which the firm declares bankruptcy $\left(\varepsilon_{t}^{m}\right)$, and the distribution range levels given by $\underline{\varepsilon}$ and $\bar{\varepsilon}$. Finally, required reserve and IOR policy affect the loan rate through the deposit rate, that affects the equity rate. A higher IOR, or a lower required reserve ratio, raise the deposit and equity rates and this raises the loan rate, thus reducing the demand for loans.

Note that the loan spread in much of the related literature is given as a mark-up over intermediation costs. In Gerali, Neri, Sessa and Signoretti (2010), and Angelini and Gerali (2011), for example, the loan spread is a function of only the pecuniary penalty for deviating from $\gamma_{t}^{r e g}$ (i.e. $R_{t}^{l}-R_{t}^{c b}=\varphi(\cdot) e_{t}$ ), whereas here, the loan spread is endogenously affected by all interest rates in the financial market and all monetary policy instruments: the interbank rate, the IOR, and the required reserve ratio. Most importantly the loan spread is endogenously driven by the probability of default. This a key feature in this model, as the probability of default, $\Phi_{t}$, is a function of the loan rate itself, $\left(\Phi_{t}\left(\varepsilon_{t}^{m}\left(R_{t}^{l}\right)\right)\right)$

\footnotetext{
${ }^{14}$ The cut-off value $\varepsilon_{j, t}^{m}$ depends on the state of the economy and hence it is identical across all firms. Similarly, real wages and the labour employed by each firm, are identical and therefore the volume of lending by the bank will also be the same. Thus, we drop the subscript $j$ in what follows.
} 
and it also affects the equity rate, $R_{t}^{e}$.

The Bank's Default Probability At the end of each period, the representative bank may be forced to liquidation if the collateral received by the defaulting firm is smaller than the bank's end-of-period financial obligations. Because the bank's total funds are provided to identical firms and the loan rate has been derived from break even conditions, (i.e. the bank's loan rate is set so as to meet its funding cost), it is implied that when the firm's default condition is satisfied $\left(\chi_{t} y_{j, t}<R_{t}^{l} l_{j, t}\right)$, the bank would also no longer break even (see also 31). Hence, we approximate the bank's default probability to that of the firm default probability in this model, i.e. $\Phi_{t}^{B} \approx \Phi_{t} .{ }^{15}$

\section{Financial Regulation and Macroprudential Policy}

The representative bank is subject to bank capital requirements that are set by international Basel Accords and supervised by the domestic monetary authority. In addition to global financial regulation, we allow the central bank to implement monetary policy by considering some key financial and liquidity variables, such as loans, credit growth, private sector's risk and total reserves available in the economy.

\subsection{Financial Regulation}

At the beginning of each period the bank must issue an amount of capital that satisfies the minimum bank capital adequacy ratio $\gamma_{t}^{r e g}$. Because raising bank capital is more costly than using deposits in this model, it is assumed that the bank issues equity merely to satisfy financial regulation. Thus, any fall below the regulatory requirement $\gamma_{t}^{\text {reg }}$ must be due to a negative shock in the bank capital market, such that,

$$
\gamma_{t}=\gamma_{t}^{r e g} \epsilon_{t}^{\gamma}
$$

\footnotetext{
${ }^{15}$ In a different model setup, where a large share of retained bank profits can play a substantial buffer role, or where the representative bank lends to many heterogenous firms, one could show that the bank's and firm's probability of default are different. A model of this nature would be more appropriate for examining the risk transmission from firms to banks, whereas, in this model, as with much of the related literature, we use a representative competitive bank framework to focus on how the combination of bank regulation and macroprudential policy can help stabilise the economy within the business cycle.
} 
where $\epsilon_{t}^{\gamma}$ denotes a shock to the equity-to-loan ratio. We employ a general macroprudential regulatory rule that targets the level of bank capital requirement,

$$
\gamma_{t}^{r e g}=\gamma_{t-1}^{\rho_{\gamma}}(\theta+\Phi)^{\left(1-\rho_{\gamma}\right)}\left(\frac{\Phi_{t}}{\Phi}\right)^{\gamma_{\Phi}\left(1-\rho_{\gamma}\right)}
$$

where the term $\rho_{\gamma} \in(0,1)$ is a persistence parameter and $\theta=0.08$ is the fixed bank capital-loan ratio as determined by Basel I in 1988. In addition, having derived an explicit expression for the probability of default, we allow bank capital requirements to respond endogenously to risk, $\Phi_{t}$. The latter effect captures the emphasis placed on idiosyncratic risk in Basel II and III. The elasticity, $\gamma_{\Phi} \gtrless 0$, which is determined optimally below, shows how bank regulation should respond to risk deviations from the steady state. Since in this model the probability of default and the risk premium is countercyclical, (see also Agénor, Bratsiotis and Pfajfar 2012), a $\gamma_{\Phi}<0$, would imply an easing of bank capital regulation during recession when risk is already high and higher bank capital requirements during booms, as advocated in Basel III. At the steady state, the minimum bank capital requirement under Basel II and III must also account for steady state risk $(\Phi>0)$, hence $\gamma^{r e g}=\theta+\Phi .^{16}$

\subsection{Macroprudential Monetary Policy}

The central bank is responsible for the supervision of financial regulation and for the conduct of monetary policy through the policy rate, $R_{t}^{c b}$ (which is also the interbank rate here), set according to the following macro-prudential policy rule, ${ }^{17}$

$$
R_{t}^{c b}=\left(R^{c b}\right)^{(1-\phi)}\left(R_{t-1}^{c b}\right)^{\phi}\left(\left(\frac{y_{t}}{y}\right)^{\phi_{y}}\left(\frac{\pi_{t}^{P}}{\pi^{P}}\right)^{\phi_{\pi}} X_{t}^{\phi_{X}}\right)^{(1-\phi)} \epsilon_{t}^{R},
$$

where the term $\phi \in(0,1)$ is the degree of interest rate smoothing and $\phi_{y}, \phi_{\pi}>0$ are policy coefficients measuring the relative weights on output and inflation deviations from their steady states, respectively. In addition we examine a number of other variables that the monetary authority can use as a means of macroprudential policy, including $X_{t}^{\phi_{X}}=\left(l_{t} / l\right)^{\phi_{l}},\left(l_{t-1} / l_{t}\right)^{\phi_{\Delta l}},\left(\Phi_{t} / \Phi\right)^{\phi_{\Phi}}$, where $\phi_{l}, \phi_{\Delta l}$ and $\phi_{\Phi}$ are the elasticity responses of the policy rate to, loan deviations, credit growth deviations and risk of default deviations from steady state respectively. The first of these two variables, (loan deviations and credit

\footnotetext{
${ }^{16}$ With $\Phi \approx 0.03$ in this model, $\gamma^{\text {reg }} \approx 0.11$

${ }^{17}$ This paper does not examine scenarios of extreme liquidity shortages or lower zero bound interest rate policy and so we assume that the interbank rate follows closely the policy rate, as it is usually the case.
} 
growth deviations), have been used widely in other models, (see Benes and Kumhof, 2011, Glocker, and Towbin, (2012), Kannan, Rabanal and Scott, 2012, Rubio and CarrascoGallego 2014, Angelini and Gerali 2012). In addition, having derived in this model an explicit probability of default, we also examine the case where the monetary policy takes into account the private sector's risk of default. Finally, $\epsilon_{t}^{R}$ is a normally distributed policy shock with zero mean and a constant variance.

\subsection{Liquidity Policy and Reserves}

Delegating the responsibility of financial stability to central banks may require more than just conventional monetary policy. Required reserves and interest rate on reserves are two policy instruments that have attracted attention lately for managing liquidity and financial stability. We re-examine the role of these two policy instruments within our framework which also allows for financial regulation and macroprudential policies.

\subsubsection{Required Reserves Ratio}

Some recent papers show that in addition to a fixed required ratio, (usually set between $1-3 \%$ ), required reserve policy rules that respond to key financial variables, can help promote financial stability (Gray 2011, Glocker and Towbin 2012, Chadha and Corrado, 2012, Mimir, Sunel and Taşkın 2013). We assume that at the steady state there is a required reserve ratio of $\mu^{c b}=2 \%$. In addition we consider the following general response rule for $\mu_{t}^{c b}$,

$$
\mu_{t}^{c b}=\left(\mu_{t-1}^{c b}\right)^{\rho_{\mu}}\left(\mu^{c b}\right)^{\left(1-\rho_{\mu^{c b}}\right)}\left(X_{t}^{\mu_{X}^{c b}}\right)^{\left(1-\rho_{\mu} c b\right)}
$$

where $\rho_{\mu^{C B}} \in(0,1)$ is a persistence parameter and $X_{t}^{\mu_{X}^{c b}}=\left(l_{t} / l\right)^{\mu_{l}^{c b}},\left(l_{t-1} / l_{t}\right)^{\mu_{\Delta l}^{c b}},\left(\Phi_{t} / \Phi\right)^{\mu_{\Phi}^{c b}}$, where $\mu_{l}^{c b}, \mu_{\Delta l}^{c b}$ and $\mu_{\Phi}^{c b}$ are the elasticity responses of the required reserves ratio to loan deviations, credit growth deviations and probability of default deviations from steady state respectively. ${ }^{18}$

\subsubsection{Interest Rate on Reserves (IOR)}

Interest rates on reserves have been used by a number of central banks (including the US Fed and the ECB) and have attracted more research attention in recent years (i.e. Curdia and Woodford 2011, Dutkowskya and VanHoose 2011, Kashyap and the Stein 2012). In

\footnotetext{
${ }^{18}$ For other recent works where required reserves also respond to the growth rate of bank credit, see Mimir, Sunel and Taşkın (2013). In Chadha and Corrado, (2012), required reserves respond to the interbank spread. In this model the risk premium, and thus the interbank spread, are fully endogenously determined and captured by responses to risk deviations from steady state, (i.e. $\left.\Phi_{t} / \Phi\right)$.
} 
the model we examine the responses of IOR to three different key variables, loans, credit growth and risk (probability of default):

$$
R_{t}^{\mu}=\left(R_{t-1}^{\mu}\right)^{\rho_{R^{\mu}}}\left(R^{\mu}\right)^{\left(1-\rho_{R^{\mu}}\right)}\left(X_{t}^{R_{X}^{\mu}}\right)^{\left(1-\rho_{R^{\mu}}\right)}
$$

where $\rho_{R^{\mu}} \in(0,1)$ is a persistence parameter, and $X_{t}^{R_{X}^{\mu}}=\left(l_{t} / l\right)^{R_{l}^{\mu}},\left(l_{t-1} / l_{t}\right)^{R_{\Delta l}^{\mu}},\left(\Phi_{t} / \Phi\right)^{R_{\Phi}^{\mu}}$, where $R_{l}^{\mu}, R_{\Delta l}^{\mu}$ and $R_{\Phi}^{\mu}$ are the elasticity responses of the IOR to loan deviations, credit growth deviations and probability of default deviations from steady state respectively. These policy instruments, and for all the policy rules above, are examined optimally and discussed in section 6 .

\section{Government and Aggregate Equilibrium}

The government receives taxes from households and a lump sum transfer from the monetary authority, which includes revenues from seigniorage $\left(\tau_{t}^{\mu}\right)$, net of interest payment to commercial banks, and any potential revenues from pecuniary penalties imposed on the banks for deviating from financial regulation, hence,

$$
\begin{aligned}
\tau_{t} & =g_{t}-\tau_{t}^{\mu}-\varphi_{0}\left(\frac{\gamma_{t}^{r e g}}{\gamma_{t}}\right)^{\varphi_{\gamma}} \text { for } \gamma_{t}^{r e g}>\gamma_{t}, \\
\tau_{t} & =g_{t}-\tau_{t}^{\mu}, \quad \text { otherwise. }
\end{aligned}
$$

where $g_{t}$ denotes government expenditures, determined in the short by an $A R(1)$ and in the long run set as a constant fraction of output. In addition, government transfers to households are in terms of reduced tax and are given by, $\tau_{t}^{\mu}=\mu_{t} d_{t}-R_{t-1}^{\mu} \mu_{t-1} d_{t-1}$. At equilibrium aggregate output must satisfy,

$$
y_{t}=c_{t}+i_{t}+g_{t}
$$

As the model is fully endogenous, any losses in GDP, due to monitoring costs, probability of default or credit market inefficiencies, are already accounted for in these macro aggregates. Finally, all aggregate shocks examined in this economy (except the policy shock, $\left.\epsilon_{t}^{R}\right)$ follow an $A R(1)$ process,

$$
\widehat{s_{t}}=0.8 \widehat{s_{t-1}}+x_{t}^{s}
$$

where $s_{t}=\epsilon_{t}^{z}, \epsilon_{t}^{\gamma}$ and $x_{t}^{s}$ is a normally distributed shock with zero mean and a constant variance. 


\section{The Steady State}

Table 1, shows our baseline model parameter values. Most of the parameter values follow largely the existing literature, whereas other parameter values are chosen so that in the steady state the model behaves well. Specifically, $\underline{\varepsilon}=0.85, \bar{\varepsilon}=1.15$ and $\chi=0.97$ are chosen so that $\Phi \approx 0.03$, as widely used in the literature; ${ }^{19}$

Table 1: Baseline Parameterisation

\begin{tabular}{lll}
\hline \hline Parameter & Value & Description \\
\hline \hline$\beta$ & 0.99 & Discount Factor \\
$\sigma$ & 1.00 & Intertemporal Substitution in Consumption \\
$\eta$ & 2.50 & Inverse of the Frisch Elasticity of Labour Supply \\
$\lambda_{w}$ & 6.00 & Elasticity of Demand - Labour \\
$\omega_{w}$ & 0.80 & Degree of Wage Stickiness \\
$\lambda_{p}$ & 6.00 & Elasticity of Demand - Intermediate Goods \\
$\omega_{p}$ & 0.75 & Degree of Price Stickiness \\
$\alpha$ & 0.30 & Capital Share in Production \\
$\epsilon^{z}$ & 1.00 & Average Productivity Parameter \\
$\epsilon^{\gamma}$ & 1.00 & Mean of Shock to Equity-Loan Ratio \\
$\xi_{k}$ & 2.50 & Physical Capital Adjustment Cost Parameter \\
$\delta_{0}$ & 0.03 & Scale Parameter \\
$\delta_{1}$ & 1.33 & Elasticity in Capital Utilization \\
$g_{g}$ & 0.30 & Share of Government Spending in Output \\
$\varepsilon$ & 0.85 & Idiosyncratic Productivity Shock Lower Range \\
$\bar{\varepsilon}$ & 1.15 & Idiosyncratic Productivity Shock Upper Range \\
$\chi$ & 0.97 & Proportion of Output seized in case of Default \\
$\varphi_{0}$ & 0.33 & Scale Parameter for Equity Monitoring \\
$\varphi_{\gamma}$ & 0.85 & Elasticity on Penalty for Deviations from $\gamma^{r e g}$ \\
$\theta$ & 0.08 & Bank Capital Adequacy Ratio \\
$\mu^{c b}$ & 0.02 & Steady State Required Reserves Ratio \\
$\phi$ & 0.80 & Persistence in Taylor Rule \\
$\rho_{\epsilon^{z}}$ & 0.80 & Persistence in technology shock \\
$\rho_{\epsilon^{\gamma}}$ & 0.80 & Persistence in bank capital shock \\
\hline \hline
\end{tabular}

The bank capital adequacy ratio $\theta=0.08$, is set in accordance with the Basel I Accord. For Basel II and beyond, which is what we employ here, idiosyncratic risk must also be taken into account, so at the steady state we use $\theta+\Phi \approx 0.11$. The scale parameter

\footnotetext{
${ }^{19}$ The value of $\chi=0.97$ implies that $3 \%$ of output is lost in verification costs and legal procedures when default takes place. This value is explained in more detail in Agénor, Bratsiotis and Pfajfar (2012).
} 
associated with bank capital monitoring and other such costs, $\left(\varphi_{0}=0.33\right)$, is set such that in the steady state, $\varphi_{0} \gamma>0$, (a small positive value around 0.03), captures the financial regulatory cost involved with the continuous monitoring of equity-loan levels and risk. ${ }^{20}$

The required reserve ratio at the steady state is $2 \%,\left(\mu^{c b}=0.02\right)$, which is an average ratio (usually between 1-3\%) in OECD countries. ${ }^{21}$ Total reserves are, $\mu=0.04$, and the values of $\psi_{1}$ and $\psi_{2}$ are chosen so that the initial steady state spread between the policy rate and the IOR is around $1 \%$ (see also Glocker and Towbin, 2012). ${ }^{22}$ Thus, we assume that at the steady state, $R^{c b}>R^{\mu}$. Some of the key steady state values resulting from the above parameterisation are as follows: $\Phi=0.0304, i^{D}=0.0101$, $i^{c b}=0.0102, i^{\mu}=0.0002, i^{e}=0.0417, i^{L}=0.0503, i^{c b}-i^{\mu}=0.01, i^{l}-i^{c b}=0.0401$, $c / y=0.5219, i / y=0.1781, g / y=0.30, y=2.1838 ; y^{e f f .}=2.6456, y^{g a p}=0.8254$, $c=1.1398, l=1.7327$, and $l / y=0.7934 .{ }^{23}$ Within this fully endogenous framework, an increase of the bank capital requirement by $1 \%$ is shown to reduce long-run economic growth by approximately $0.27 \% .^{24}$

\section{Policy Welfare Analysis}

In this section we consider the policy welfare implications of this model, based on three types of welfare loss functions. The first one is the widely used welfare loss function, where welfare is measured in terms of inflation and output gap deviations from its efficient level, (see Kannan, Rabanal and Scott, 2012, Glocker and Towbin 2012, Angelini, Neri and Panetta, 2014) ${ }^{25}$,

$$
\mathcal{W}_{t}^{A}=E\left[\left(\hat{\pi}_{t}^{P}\right)^{2}+\lambda_{y}\left(\hat{y}_{t}^{g a p}\right)^{2}\right]
$$

We also consider two other welfare loss functions that aim to capture some concern over financial stability, first measured in terms of loan deviations from the steady state,

$$
\mathcal{W}_{t}^{B}=E\left[\left(\hat{\pi}_{t}^{P}\right)^{2}+\lambda_{y}\left(\hat{y}_{t}^{\text {gap }}\right)^{2}+\lambda_{l}\left(\hat{L}_{t}\right)^{2}\right]
$$

\footnotetext{
${ }^{20}$ Thus, this steady state level is positive even when the bank capital requirements conditions are met, $\gamma=\gamma^{r e g}$.

${ }^{21} \mathrm{~A} 2 \%$ required reserve ratio also reflects the ratio recently proposed for the Euro Zone countries.

${ }^{22}$ This implies that $\psi_{1}=-0.02$, and $\psi_{2}=0.50$, so that $R^{c b}-R^{\mu}=0.01$.

${ }^{23}$ Note that these values are derived endogenously in the model. This includes the loan to output ratio, $l / y=0.7934$, assumed to be around 0.8 in other studies.

${ }^{24}$ This value appears on the higher side of the approximate median estimate of $0.09 \%$, suggested by Angelini, at al (2011), based on 13 callibrated models for the US and the Euro area. However, their esimates differ largely across these 13 different models and their average value is higher than their median.

${ }^{25}$ For the justification of these welfare loss functions see also Glocker and Towbin (2012)
} 
and also measured in terms of the volatility of credit growth from steady state,

$$
\mathcal{W}_{t}^{C}=E\left[\left(\hat{\pi}_{t}^{P}\right)^{2}+\lambda_{y}\left(\hat{y}_{t}^{g a p}\right)^{2}+\lambda_{\Delta l}\left(\hat{L}_{t}-\hat{L}_{t-1}\right)^{2}\right] .
$$

where $\hat{y}_{t}^{\text {gap }}=\hat{y}_{t}-\hat{y}_{t}^{*}$ is output gap deviations from its efficient level, $\hat{y}_{t}^{*}=\hat{z}_{t}+\alpha\left(\hat{u}_{t}^{*}+\right.$ $\left.\hat{k}_{t-1}^{*}\right)+(1-\alpha) \hat{n}_{t}^{*}$, and $\lambda_{y}, \lambda_{l}$, and $\lambda_{\Delta l}$ are subjective weights measuring the policy makers preferences on stabilizing the output gap, loans deviations or credit growth deviations, respectively. In what follows we employ, $\lambda_{y}=0.25$ and $\lambda_{l}=\lambda_{\Delta l}=0.1$. The value of $\lambda_{y}=0.25$ on the output gap, is widely used in the literature (see McCallum and Nelson 2000, Jensen 2002, Walsh 2003, Ravenna and Walsh 2006). ${ }^{26}$ For the weight on financial stability we choose a value that is slightly lower than that on the output gap, $\lambda_{l}=\lambda_{\Delta l}=0.1$. This moderate weight is sufficient to highlight how optimal policy can vary, as we move from a welfare loss that attaches zero weight on financial stability to some concern over financial stability.

Table 2 shows the optimal policy combinations, out of all policy rules (38), (39), (40) and (41), for minimising the three different type of welfare loss functions above, following three types of shocks: a negative technology shock, a rise in the policy rate, and a fall in the bank capital ratio. Our analysis is based on a grid search over constrained optimal policies, which are confined to plausible values. ${ }^{27}$ Under each of the three welfare loss functions considered and under each type of shock, Table 2 shows the welfare loss value under a simple Taylor rule, with $\phi_{\pi}=1.5$ and $\phi_{y}=0.2$, and all other policy parameters set to zero and below this, the welfare loss values of the optimal combination of policy responses. The results in Table 2 are then analysed in terms of the type of shock, in the following subsections where simulations are presented. The simulations in Figures 1-3 are based on the standard welfare loss type, $\mathcal{W}_{t}^{A} \cdot{ }^{28}$

\footnotetext{
${ }^{26}$ Note that although their theoretical model of Ravenna and Walsh (2006) implies a value of $\lambda_{y}=$ 0.0195 , they too decide to employ the value, $\lambda_{y}=0.25$.

${ }^{27}$ The optimal parameters are searched within the following ranges: $\phi_{\pi} \in[1,3], \phi_{y} \in[0,1], \phi_{l}, \phi_{\Delta l} \in$ $[0,1], \phi_{\Phi} \in[-1,0], \gamma_{\Phi} \in[-3,3], \mu_{l}^{c b}, \mu_{\Delta l}^{c b}, \mu_{\Phi}^{c b} \in[-10,10], R_{l}^{\mu}, R_{\Delta l}^{\mu}, R_{\Phi}^{\mu} \in[-10,10]$. Note that, as with other similar models, plausible range parameter values need to be imposed, particularly because of the nature of this model that considers a fully credit-driven economy (i.e. all working capital is covered by borrowing). Note that allowing the range of these parameter take extreme values, makes negligible differences in further reducing welfare losses and no qualitative differences in our results.

${ }^{28}$ In all simulations, the blue solid line represents the standard Taylor Rule case (with assumed values $\phi_{\pi}=1.5$ and $\phi_{y}=0.2$ ), whereas the red dotted line represents the optimal combination for $\mathcal{W}_{t}^{A}$, under each shock.
} 
Table 2: Welfare Losses: Optimal Policy Combinations

\begin{tabular}{|c|c|c|}
\hline Technology Shocks & Policy Shocks & Bank Capital Shocks \\
\hline \multicolumn{3}{|c|}{$\mathcal{W}_{t}^{A}=E\left[\left(\hat{\pi}_{t}^{P}\right)^{2}+0.25\left(\hat{y}_{t}^{g a p}\right)^{2}\right]$} \\
\hline \multicolumn{3}{|c|}{ Standard Taylor Rule (Non-optimal: $\phi_{\pi}=1.5$ and $\phi_{y}=0.2$ ) } \\
\hline Loss $=1.3451$ & Loss $=3.1584$ & Loss $=0.0045$ \\
\hline \multicolumn{3}{|c|}{ Optimal Policy Combination } \\
\hline$\phi_{\pi}=3$ & $\phi_{\pi}=3$ & $\phi_{\pi}=1$ \\
\hline$\phi_{y}=0.07$ & $\phi_{y}=1$ & $\phi_{y}=1$ \\
\hline$R_{l}^{\mu}=3.6$ & $\phi_{l}=1$ & $\phi_{l}=0.07$ \\
\hline$\gamma_{\Phi}=-3$ & $R_{l}^{\mu}=6.3$ & $R_{l}^{\mu}=-1.2$ \\
\hline$\sim$ & $\gamma_{\Phi}=-0.09$ & $\gamma_{\Phi}=-3$ \\
\hline Loss $=0.0130$ & Loss $=0.0310$ & Loss $=1.25 \times 10^{-4}$ \\
\hline \multicolumn{3}{|c|}{$\mathcal{W}_{t}^{B}=E\left[\left(\hat{\pi}_{t}^{P}\right)^{2}+0.25\left(\hat{y}_{t}^{g a p}\right)^{2}+0.1\left(\hat{L}_{t}\right)^{2}\right]$} \\
\hline \multicolumn{3}{|c|}{ Standard Taylor Rule (Non-optimal: $\phi_{\pi}=1.5$ and $\phi_{y}=0.2$ ) } \\
\hline Loss $=4.8654$ & Loss $=4.7701$ & Loss $=0.4064$ \\
\hline \multicolumn{3}{|c|}{ Optimal Policy Combination } \\
\hline$\phi_{\pi}=3$ & $\phi_{\pi}=1$ & $\phi_{\pi}=1$ \\
\hline$\phi_{y}=0.2$ & $\phi_{y}=1$ & $\phi_{y}=1$ \\
\hline$R_{l}^{\mu}=2.8$ & $\phi_{l}=1$ & $\phi_{l}=1$ \\
\hline$\gamma_{\Phi}=-3$ & $R_{l}^{\mu}=10$ & $R_{l}^{\mu}=-8.1$ \\
\hline$\sim$ & $\gamma_{\Phi}=-3$ & $\gamma_{\Phi}=-3$ \\
\hline Loss $=0.3522$ & Loss $=0.2170$ & Loss $=0.0051$ \\
\hline \multicolumn{3}{|c|}{$\mathcal{W}_{t}^{C}=E\left[\left(\hat{\pi}_{t}^{P}\right)^{2}+0.25\left(\hat{y}_{t}^{g a p}\right)^{2}+0.1\left(\hat{L}_{t}-\hat{L}_{t-1}\right)^{2}\right]$} \\
\hline \multicolumn{3}{|c|}{ Standard Taylor Rule (Non-optimal: $\phi_{\pi}=1.5$ and $\phi_{y}=0.2$ ) } \\
\hline Loss $=3.6719$ & Loss $=4.0648$ & Loss $=0.2590$ \\
\hline \multicolumn{3}{|c|}{ Optimal Policy Combination } \\
\hline$\phi_{\pi}=3$ & $\phi_{\pi}=3$ & $\phi_{\pi}=3$ \\
\hline$\phi_{y}=0$ & $\phi_{y}=1$ & $\phi_{y}=1$ \\
\hline$\phi_{\Delta l}=0.16$ & $\phi_{\Delta l}=1$ & $\phi_{\Delta l}=1$ \\
\hline$R_{\Delta l}^{\mu}=10$ & $R_{\Delta l}^{\mu}=-10$ & $R_{\Delta l}^{\mu}=4$ \\
\hline$\gamma_{\Phi}=-0.9$ & $\sim$ & $\gamma_{\Phi}=-3$ \\
\hline Loss $=0.5404$ & Loss $=0.7863$ & Loss $=0.002$ \\
\hline
\end{tabular}

\subsection{Technology Shocks}

Looking first at the standard Taylor rule, under welfare loss, $\mathcal{W}_{t}^{A}$ in Table 2, (blue solid line in Figure 1), a 1\% negative technology shock increases inflation and the output gap 
and reduces output, this raises the probability of default and raises the loan rate.

Figure 1: $1 \%$ negative technology shock
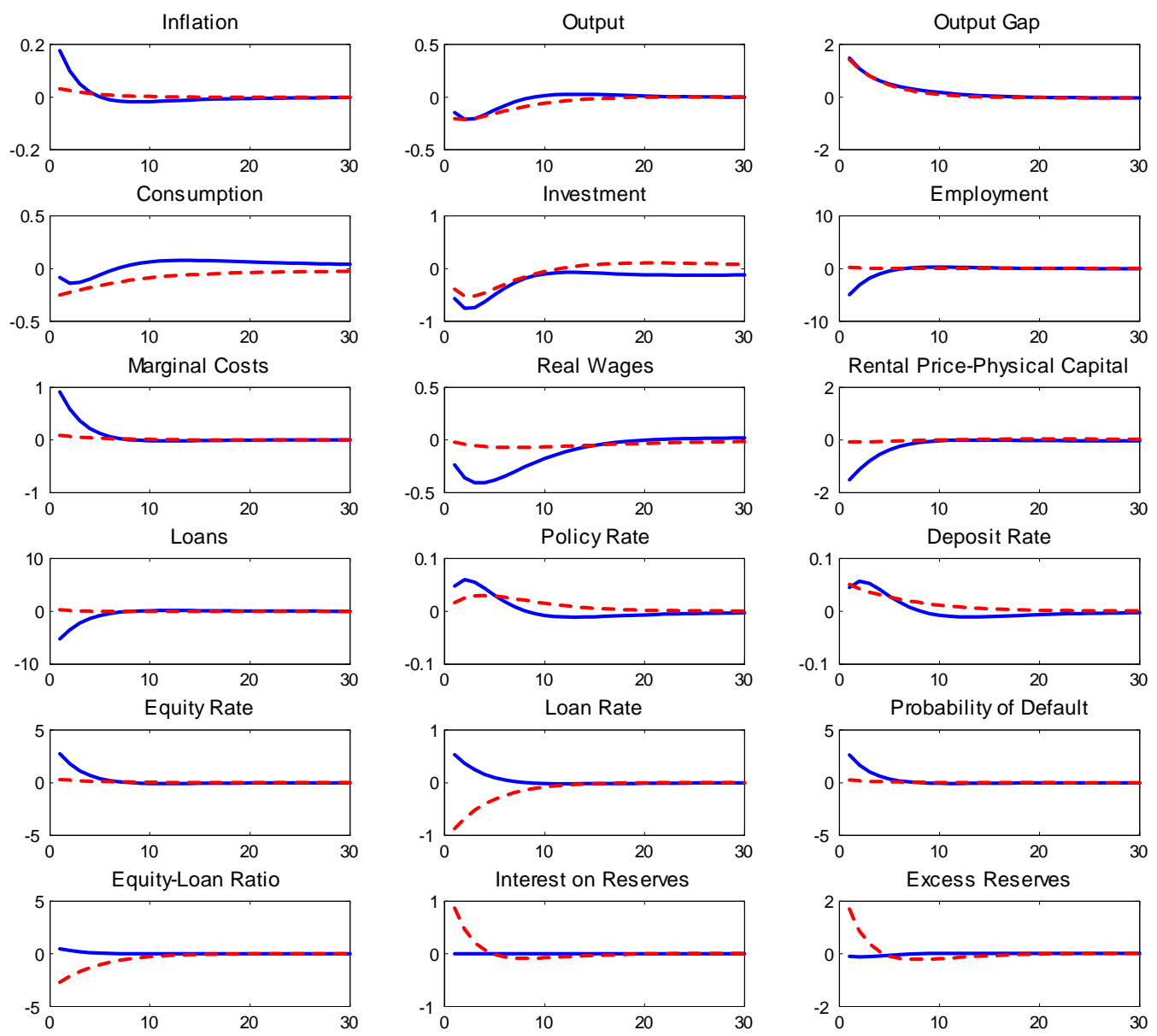

The higher loan rate increases marginal cost and further raises inflation through the cost channel effect in this model. In the financial markets, the higher probability of default raises further the loan rate (through the financial accelerator effect) and this reduces the available credit in the economy, with a sharp fall in loans. The higher risk of default also increases the equity-loan ratio $(\gamma)$ and pushes up the equity rate, which in turn also raises the loan rate. If the welfare loss is measured mostly by inflation, with some weight on the output gap (see $\mathcal{W}_{t}^{A}$ in Table 2), then our results suggest that the best optimal policy combination, is a macroprudential mix of strong anti-inflation policy combined with policy and financial regulation aiming to encourage 'controlled' credit growth, (see red dotted line in figure 1). Specifically, the optimal policy combination 
here is a strong responses of the policy rate $\left(R_{t}^{c b}\right)$ to the rising inflation $\left(\phi_{\pi}=3\right)$, that is however moderated slightly with respect to the falling output $\left(\phi_{y}=0.07\right)$. The rise in the policy rate $\left(R_{t}^{c b}\right)$ must be supported by an easing of the bank capital requirements with respect to the sudden rise in the probability of default $\left(\gamma_{\Phi}=-3\right)$ so as to boost the available liquidity in the economy and appease the financial markets. The fall in the equity-loan ratio causes an increase in the level of loans and this reduces the loan rate and through the cost channel effect this also reduces marginal cost and inflation. With lower bank capital requirements and rising loans, a rise in IOR (a positive response with respect to the rising loans, $R_{l}^{\mu}=3.6$ ), is important as a higher IOR raises excess reserves and controls liquidity around its long-run level. This also allows the policy rate $R_{t}^{c b}$ to be less aggressive (compare blue and red lines).

Similar policy combinations are suggested when we consider welfare loss functions, $\mathcal{W}_{t}^{B}$ and $\mathcal{W}_{t}^{C}$, (not shown in the simulations), where some weight is also attached to financial stability, although the emphasis here changes slightly. In the first case where welfare is measured by loan deviation from steady state, $\left(\mathcal{W}_{t}^{B}\right)$, the moderation of the policy rate with respect to output is higher. This is intuitive because loans are procyclical and so such policy can help reduce loan deviation from their steady state. If financial stability is measured by credit growth, $\left(\mathcal{W}_{t}^{C}\right)$, then less emphasis is placed on responses to output and financial regulation, (both connected to the level of loans) and more emphasis is placed on the growth of credit, with both the policy rate and the IOR responding procyclically to credit growth, (i.e. $\phi_{\Delta l}=0.16$ and $R_{\Delta l}^{\mu}=10$ ).

\subsection{Policy Shocks}

With the standard Taylor rule first, based on welfare loss, $\mathcal{W}_{t}^{A}$, (Table 2, blue solid line in Figure 2), a $1 \%$ rise in the interest rate reduces output and inflation but also raises all interest rates: the deposit rate, the equity rate and the loan rate. The higher deposit rate reduces consumption and investment, whereas the higher equity rate increases the loan rate and reduces the quantity of loans. The equity-loan ratio, driven by regulation, is shown to fall slightly here because of a slight fall in the overall risk of default, which occurs because the large fall in loans makes the total cost of borrowing drop more than output. 
Figure 2: $1 \%$ negative policy shock
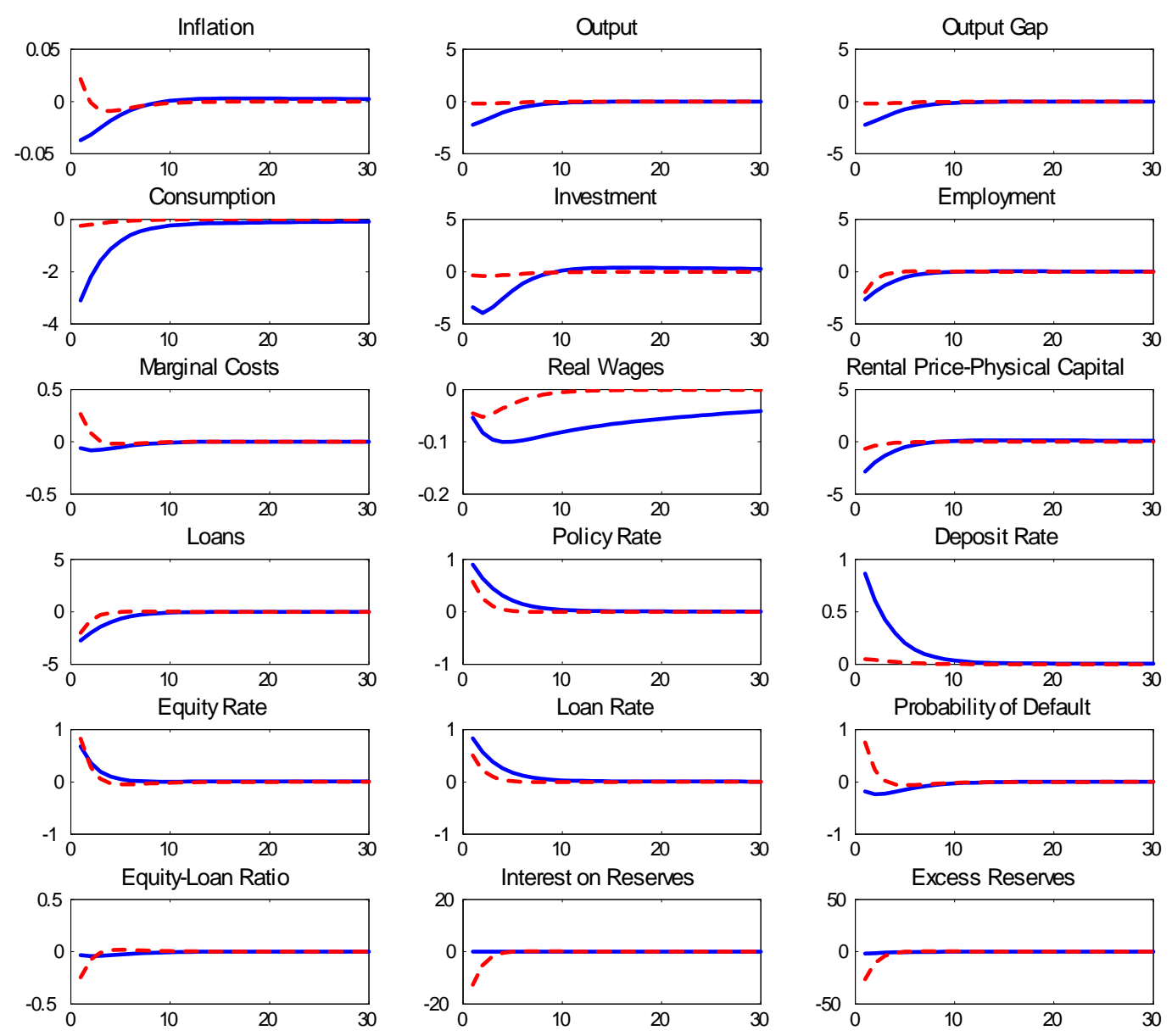

Looking first at welfare loss $\mathcal{W}_{t}^{A}$, (Table 2 and red dotted line in Figure 2), our results suggest that the best optimal policy is a macro-prudential mix with a rise in the policy rate responding strongly to the inflation rate $\left(\phi_{\pi}=3\right)$, moderated in response to the falling output and loans, $\left(\phi_{y}=1, \phi_{l}=1\right)$, combined with a reduction in the IOR with respect to the falling volume of loans $\left(R_{l}^{\mu}=6.3\right)$, so as to boost liquidity. The higher policy rate aims to tackle inflation, whereas a reduction in the IOR, which reduces the deposit rate and the level of excess reserves, will help boost liquidity while stabilise consumption, investment and output. The increase in liquidity raises the volume of loans. This policy, combined with the high loan rate, may initially raise the risk of default, but as the equity-loan ratio reverts to its higher long run value, so does the probability of 
default. With a high probability of default and already low output, a slight easing of the bank capital requirements is also suggested, (a response of $\gamma_{\Phi}=-0.09$ ).

With welfare loss, $\mathcal{W}_{t}^{B}$, the optimal policy combination requires relatively stronger responses of the policy rate, the IOR and bank regulation with respect to loan deviations, whereas with welfare $\mathcal{W}_{t}^{C}$ more emphasis is placed on credit growth, as in the case of the other shocks.

\subsection{Bank Capital Shocks}

Here we consider a $10 \%$ fall in the equity-to-loan ratio $\left(\epsilon_{t}^{\gamma}\right)$. Looking first at the standard Taylor rule case, with welfare loss $\mathcal{W}_{t}^{A}$ (Table 2, blue solid line in Figure 3), the fall in the equity-loan ratio, increases the probability of default which raises the equity and loan rates. The higher loan rate pushes up marginal cost and inflation, but it also reduces the demand for loans. The rise in inflation results in a higher policy rate and this raises the deposit and other rates which reduce output, consumption and employment. At first glance, a sudden drop in the equity-loan ratio appears to have a similar effect to a negative technology shock, with output falling and inflation rising. However, unlike the technology shock earlier, the inflation-output trade off here is much smaller. In addition, by the nature of this shock, the equity-loan ratio drops to a level that is much lower than that reflecting the actual risk of default in the economy. If the IOR and financial regulation are available as policy instruments, then the optimal policy following a bank capital shock is not to overreact by raising the policy rate (as in blue line in figure 3) but to follow a much milder response (see red dotted line, with $\phi_{\pi}=1$, and $\phi_{y}=1$ and $\left.\phi_{l}=0.07\right)$, thus keeping the policy rate low, while raising the IOR so as to prevent the credit markets from overheating. Keeping a low policy rate also implies relatively lower loan and equity rates and this starts boosting the volume of credit towards its steady state level. A higher IOR, (i.e. $R_{l}^{\mu}=-1.2$ in response to the fall in loans), is required to help regulate the rise in liquidity and stabilise the credit markets. This also allows the policy rate to target inflation without the need of higher policy rates (see blue line) that can harm the real economy. Note that because here the negative bank capital shock reduced, by definition, the equity-loan ratio and this exposed a high probability of default, the optimal response of bank regulation is to initially lower its requirements with respect to the high risk of default while the economy remains in recession; the opposite effect would lead to a worsening of the recession and thus an amplified risk of default (compare blue 
and red lines).

Figure 3: $10 \%$ negative bank capital shock
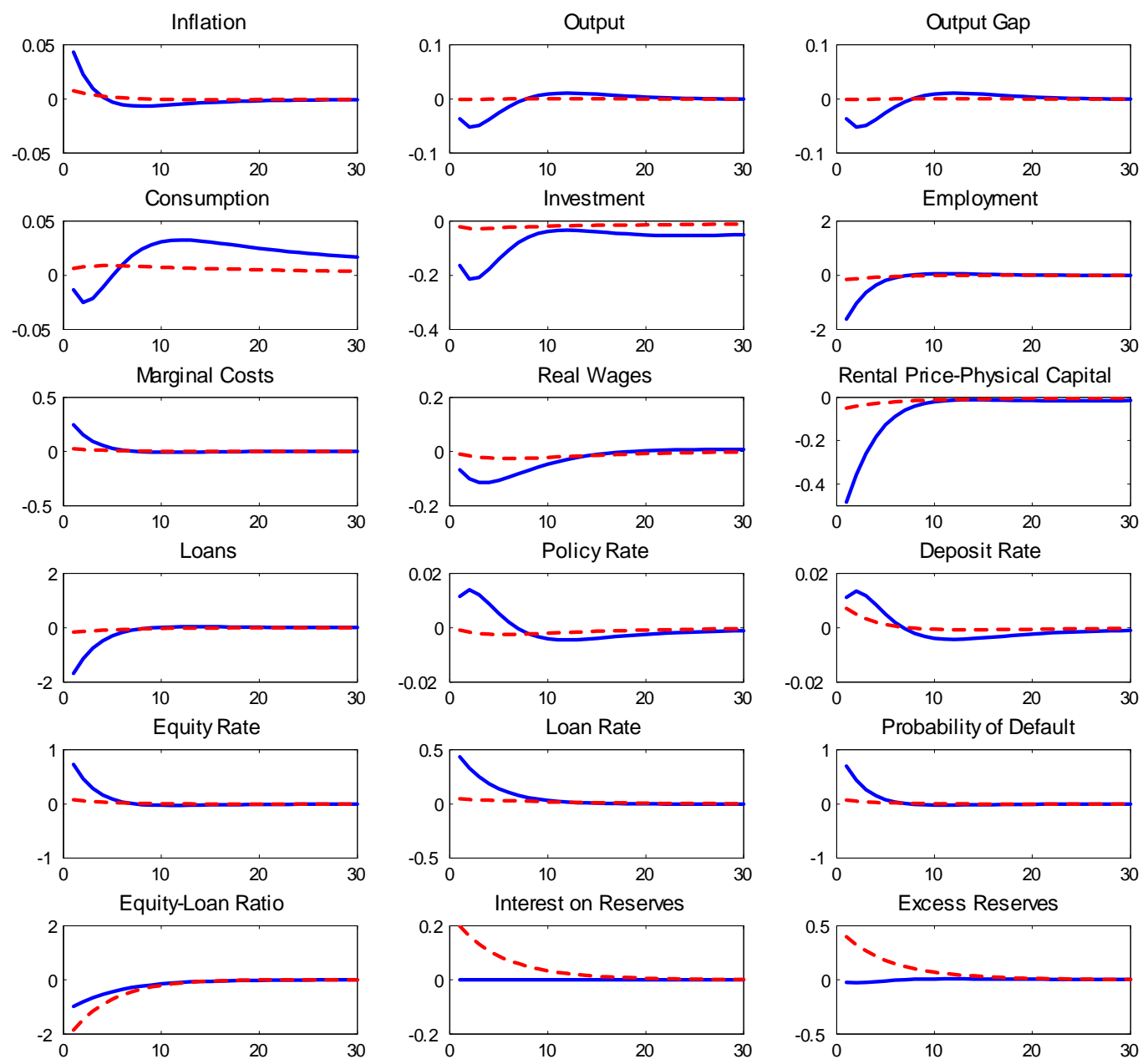

With welfare, $\mathcal{W}_{t}^{B}$, more emphasis is placed on the volume of loans deviating from their steady state, and so a further easing of the policy rate with respect to the fall in loans $\left(\phi_{l}=1\right)$; this is supported by an easing of bank capital requirements, $\left(\gamma_{\Phi}=-3\right)$, combined with a higher IOR to regulate liquidity. In welfare case $\mathcal{W}_{t}^{C}$, the policy intuition is the same as before, with more emphasis on inflation rather than on output and stronger responses of these policy instruments to deviations in credit growth. 


\section{Concluding Remarks}

This paper considers a credit-driven economy where the 'lender' bank and its equity holders are exposed to risk from 'borrower' firms. The risk premia driving the loan and equity spreads are shown to reflect these risks, which in this model are endogenously affected by the borrowers' probability of default but also by financial regulation and macro prudential policy parameters. The latter policies are examined under various welfare loss minimising combinations and types of shocks. The results emphasize the need for coordination between the financial regulation and monetary policy authorities. It is shown that even when there is no immediate concern over financial stability, (with welfare measured only in terms of inflation and output gap), policy coordination between the financial regulation and monetary policy is crucial for minimising welfare losses, following real and financial shocks.

The paper also highlights a significant policy role for interest on reserves (IOR). Even when bank regulation and macroprudential policy responses are active, real and financial stability, but also welfare, can all be improved when the monetary authority uses interest on reserves (IOR) to stabilise the economy following shocks. This result reinforces the findings in Ireland (2011), as the latter paper does not consider the importance of IOR within a framework where financial regulation and other macroprudential options coexist. Crucial to this result is the fact that IOR can target directly the deposit rate and hence the level of excess reserves and liquidity allowing the policy rate to target inflation. This provides the central bank with an extra degree of freedom to control credit volatility and stabilise the real and financial markets without requiring aggressive changes in the policy rate. The results also suggest that the IOR is a more effective policy instrument in reducing welfare losses than required reserves.

In terms of financial regulation, the results suggest a countercyclical response of bank capital ratio to the probability of default, following real and financial shocks. When output falls, the probability of default rises in this model, thus such policy implies an easing of bank capital regulation in times of recessions, where output is low and the risk of default is already high, and a stricter bank regulation during boom periods; a result that is not inconsistent with the spirit of Basel III. 


\section{References}

[1]Agénor, P.R., G.J. Bratsiotis and D. Pfajfar (2012), "Credit Frictions, Collateral and the Cyclical Behaviour of the Finance Premium", Macroeconomic Dynamics, 18, 5, pp 985-997.

[2]Aliaga-Diaz, Roger and Olivero, Maria P. (2012). "Do Bank Capital Requirements Amplify Business Cycles? Bridging the Gap Between Theory and Empirics", Macroeconomic Dynamics, 16.3, 358-395.

[3] Angelini P., L. Clerc, V. Cúrdia, L. Gambacorta, A. Gerali, A. Locarno, R. Motto, W. Roeger, S. Van den Heuvel and J. Vlček, (2014) "Basel III: Long-term Impact on Economic Performance and Fluctuations" The Manchester School, DOI: 10.1111/manc. 12056 .

[4]Angelini, P, S. Neri, and F. Panetta. (2014). "The Interaction between Capital Requirements and Monetary Policy", Journal of Money, Credit and Banking, 46(6), 1074-1112.

[5]Angelini, P., Neri, S., and Panetta, F. (2011). Monetary and macroprudential policies. Bank of Italy Temi di Discussione (Working Paper) No, 801.

[6]Angeloni, I. and E. Faia (2009), "A Tale of Two Policies: Prudential Regulation and Monetary Policy with Fragile Banks", mimeo, European Central Bank.

[7]Benes, J., and Kumhof, M. (2011). Risky bank lending and optimal capital adequacy regulation. International Monetary Fund.

[8]Bernanke, B., M. Gertler and S. Gilchrist (1999), "The Financial Accelerator in a Quantitative Business Cycle Framework", In J.B. Taylor and M. Woodford (Eds), Handbook of Macroeconomics, Vol. 1C, pp. 1341-1393, Amsterdam, North Holland (Elsevier).

[9]Board of Governors of the Federal Reserve System. 2008. Press Release, October 6, (http://www.federalreserve.gov/newsevents/press/monetary/20081006a.htm)

[10]Chadha, Jagjit S. \& Corrado, Luisa, 2012. "Macro-prudential policy on liquidity: What does a DSGE model tell us?," Journal of Economics and Business, Elsevier, vol. 64(1), pages 37-62.

[11]Christiano, L.J., M. Eichenbaum and C. Evans (2005), "Nominal Rigidities and the Dynamic Effects of a Shock to Monetary Policy", Journal of Political Economy, 113, pp. $1-45$.

[12]Christiano, L.J., R. Motto and M. Rostagno (2008), "Shocks, Structures, or Monetary Policies? The Euro Area and U.S. After 2001", Journal of Economic 
Dynamics and Control, 32, pp. 2476-2506.

[13]Covas, F. and S. Fujita (2010), "Procyclicality of Capital Requirements in a General Equilibrium Model of Liquidity Dependence", International Journal of Central Banking, 6(4), pp. 137-173.

[14]Curdia, V., and Woodford, M. (2011). "The central-bank balance sheet as an instrument of monetary policy". Journal of Monetary Economics, 58(1), 54-79.

[15]Dib, A (2010), "Capital Requirements and Financial Frictions in Banking", unpublished, Central Bank of Canada.

[16]Drumond, I. (2009), "Bank Capital Requirements, Business Cycle Fluctuations and the Basel Accords: A Synthesis", Journal of Economic Surveys, 23(5), pp. 798-830.

[17]Dutkowsky, D. H., and VanHoose, D. D. (2011). "Interest on bank reserves and optimal sweeping". Journal of Banking \& Finance, 35(9), 2491-2497.

[18]Erceg, C.J., D. Henderson and A. T. Levin (2000), "Optimal monetary policy with staggered wage and price contracts", Journal of Monetary Economics, 46, pp. 281-313.

[19]Fiore, F. D., and Tristani, O. (2013). "Optimal monetary policy in a model of the credit channel". The Economic Journal, 123(571), 906-931.

[20]Gerali, A., S. Neri, L. Sessa and F.M. Signoretti (2010), "Credit and Banking in a DSGE model of the Euro Area", Journal of Money, Credit and Banking, 42(s1), pp. 107-141.

[21]Glocker, C. and P. Towbin, (2012), "Reserve Requirements for Price and Financial Stability: When Are They Effective?," International Journal of Central Banking, Vol. 8, No. 1, pp. 65-114.

[22] Goodfriend, Marvin (2002), Interest on reserves and monetary policy. Federal Reserve Bank of New York Economic Policy Review 8, 77-84.

[23]Ireland, P. N., (2011), "The macroeconomic effects of interest on reserves." Macroeconomic Dynamics (2011): 1-42.

[24]Jensen, H., (2002), "Targeting Nominal Income Growth or Inflation?", American Economic Review, 92, 928-956.

[25]Kannan, P., P. Rabanal, and A.M. Scott, (2012), "Monetary and Macroprudential Policy Rules in a Model with House Price Booms", The B.E. Journal of Macroeconomics: Vol. 12: Iss. 1 (Contributions), Article 16.

[26]Kashyap, A., and J. Stein. (2012). "The Optimal Conduct of Monetary Policy with Interest on Reserves." American Economic Journal: Macroeconomics 4 (1): 266-82. [27]McCallum, B. T., and Nelson, E. (2000). "Timeless perspectives vs. discretionary 
monetary policy in forward-looking models" (No. w7915). National Bureau of Economic Research.

[28]Meh, C. and K. Moran (2010), "The Role of Bank Capital in the Propagation of Shocks", Journal of Economic Dynamics and Control, 34(3), pp. 555-576.

[29]Mimir, Y., Sunel, E., \& Taşkın, T. (2013). "Required reserves as a credit policy tool. The BE Journal of Macroeconomics", 13(1), 823-880.

[30]Darracq-Paries, M., C. Kok Sørensen, and D. Rodriguez-Palenquela (2011).

"Macroeconomic Propagation under Different Regulatory Regimes: Evidence from an Estimated DSGE Model for the Euro Area", International Journal of Central Banking 7 (4): 49-113.

[31]Ravenna, F. and C. E. Walsh (2006), "Optimal Monetary Policy with the Cost Channel", Journal of Monetary Economics, 53, pp. 199-216.

[32]Repullo, R., and Suarez, J. (2013). "The procyclical effects of bank capital regulation". Review of Financial Studies, 26(2), 452-490.

[33]Rubio, M., J.A. Carrasco-Gallego (2014). "Macroprudential and monetary policies: Implications for financial stability and welfare", Journal of Banking \& Finance, (DOI: 10.1016/j.jbankfin.2014.02.012)

[34]Smets, F. and R. Wouters (2003), "An Estimated Stochastic General Equilibrium Model of the Euro area", Journal of the European Economic Association, 1(5), pp. 1123-1175.

[35]Walsh, C. E., 2003, "Speed Limit Policies: The Output Gap and Optimal Monetary Policy", American Economic Review 93, 265-278. 


\section{Appendix}

\section{The Steady State}

From the Euler Equation,

$$
R^{d}=\frac{1}{\beta}
$$

From the bank's optimisation problem

$$
R^{d}=(1-\mu) R^{c b}+\mu R^{\mu}-G^{\mu}
$$

Adjustment costs for adjusting reserves,

$$
G^{\mu}=\psi_{1}\left(\mu-\mu^{c b}\right)+\frac{\psi_{2}}{2}\left(\mu-\mu^{c b}\right)^{2}, \psi_{1}<0 \text { and } \psi_{2}>0 .
$$

Total Reserves,

$$
\mu=\mu^{c b}-\frac{\psi_{1}}{\psi_{2}}-\frac{\left(R^{c b}-R^{\mu}\right)}{\psi_{2}}, \psi_{1}<0 \text { and } \psi_{2}>0
$$

where required reserves are, $\mu^{c b}=0.02$ and excess reserves,

$$
\mu^{E R} \equiv \mu-\mu^{c b}
$$

Equity Rate,

$$
R^{e}=\frac{R^{d}}{(1-\Phi)}
$$

Loan Rate,

$$
R^{l}=R^{c b}+\left(R^{e}-R^{c b}+\varphi_{0}\right) \gamma+\frac{\chi z \bar{k}^{\alpha} n^{1-\alpha}}{l}\left(\frac{\bar{\varepsilon}-\underline{\varepsilon}}{2}\right) \Phi^{2}
$$

Output,

$$
y=z \bar{k}^{\alpha} n^{1-\alpha} .
$$

Average productivity

$$
z=a\left(\frac{\bar{\varepsilon}+\underline{\varepsilon}}{2}\right)=a \mu_{\varepsilon}
$$

which given the assumptions of the model reduce to $z=1$.

Capital-labour ratio, determines $\bar{k}$.

$$
\frac{\bar{k}}{n}=\frac{\alpha}{(1-\alpha)} \frac{w}{r^{k}} .
$$


Wages (at the flexible steady state),

$$
w=\left(\frac{\lambda_{w}}{\lambda_{w}-1}\right)\left(1+\tau^{w}\right) m r s
$$

where $m r s=n^{\eta} c^{\frac{1}{\sigma}}$ and $\left(\frac{\lambda_{w}}{\lambda_{w}-1}\right)\left(1+\tau^{w}\right)=1$.Rental Price of capital,

$$
r^{k}=\delta_{0} \delta_{1}=\frac{1}{\beta}-1+\delta_{0} .
$$

Utilization depreciation (from the above),

$$
\delta_{1}=1+\frac{\frac{1}{\beta}-1}{\delta_{0}} .
$$

Total Loans,

$$
l=r^{k} \bar{k}+w n
$$

Investment,

$$
i=\delta_{0} \bar{k}
$$

Taxes,

$$
\tau=g-\tau^{\mu}+\varphi_{0}
$$

Revenues from seigniorage,

$$
\tau^{\mu}=\left(1-R^{\mu}\right) \mu d
$$

Consumption,

$$
c=y-i-g .
$$

Marginal cost,

$$
m c=\frac{\left(1+i^{l}\right)\left(r^{k}\right)^{\alpha}(w)^{1-\alpha}}{\alpha^{\alpha}(1-\alpha)^{1-\alpha} z}=\frac{\lambda_{p}-1}{\lambda_{p}} .
$$

Price mark-up,

$$
\vartheta_{p}=\frac{1}{m c}=\frac{\lambda_{p}}{\lambda_{p}-1} .
$$

Cut-off point of default, using $m c=\frac{1}{\vartheta_{p}}$ and $\mu_{\varepsilon}=\left(\frac{\bar{\varepsilon}+\varepsilon}{2}\right)$,

$$
\varepsilon^{M}=\frac{\mu_{\varepsilon}}{\chi \vartheta_{p}}
$$

Probability of default,

$$
\Phi=\frac{\varepsilon^{M}-\underline{\varepsilon}}{\bar{\varepsilon}-\underline{\varepsilon}} .
$$

Bank capital regulatory ratio,.

$$
\gamma^{r e g}=\theta+\Phi
$$


Deposits,

$$
d=\frac{l-e}{(1-\mu)} .
$$

Bank equity

$$
e=(\theta+\Phi) l \text {. }
$$

Government spending,

$$
g / y=0.3 .
$$

\subsection{Efficient Steady State (for the output gap)}

Euler Equation,

$$
1=\beta\left[\left(1-\delta_{0} u^{\delta_{1}}\right)+\alpha z u\left(\frac{n}{u k}\right)^{1-\alpha}\right]
$$

Labour Supply,

$$
(1-\alpha) z\left(\frac{u k}{n}\right)^{\alpha}=\frac{n^{\eta}}{c^{-\frac{1}{\sigma}}}
$$

Capital Utilization,

$$
\alpha z\left(\frac{n}{u k}\right)^{1-\alpha}=\delta_{0} \delta_{1} u^{\delta_{1}-1}
$$

Resource Constraint,

$$
z(u k)^{\alpha} n^{1-\alpha}=c+k-\left(1-\delta_{0} u^{\delta_{1}}\right) k+g
$$

These four equations solve for the efficient steady state levels of $n^{*}, k^{*}, c^{*}$ and $u^{*}$, from which we solve for the efficient steady state level of output,

$$
y^{*}=z\left(u^{*} k^{*}\right)^{\alpha}\left(h^{*}\right)^{1-\alpha}
$$

The output gap at steady state will be defined as,

$$
y^{g}=\frac{y}{y^{*}}
$$

where $y$ is the steady state level of output from the (non-efficient) model.

\section{Log-Linearizations}

Consumption

$$
\hat{c}_{t}=\hat{c}_{t+1}-\sigma\left(\hat{R}_{t}^{d}-\hat{\pi}_{t+1}^{P}\right)
$$

Evolution of capital,

$$
\hat{k}_{t}=\left(1-\delta_{0}\right) \hat{k}_{t-1}-\delta_{0} \delta_{1} \hat{u}_{t}+\frac{i}{k} \hat{\imath}_{t}
$$


The first order condition with respect to $u_{t}$,

$$
\hat{\lambda}_{t}^{c}-\hat{\lambda}_{t}^{k}+\hat{r}_{t}^{k}=\left(\delta_{1}-1\right) \hat{u}_{t}
$$

The first order condition with respect to $k_{t}$ (normalizing $u=1$ ),

$$
\hat{\lambda}_{t}^{k}=\beta\left\{r^{k} \hat{\lambda}_{t+1}^{c}+\left(r^{k}-\delta_{0} \delta_{1}\right) \hat{u}_{t+1}+r^{k} \hat{r}_{t+1}^{k}+\left[1-\delta_{0}\right] \hat{\lambda}_{t+1}^{k}\right\}
$$

The first order condition with respect to $i_{t}$, and using $\frac{\lambda^{c}}{\lambda^{k}}=1$,

$$
\hat{\lambda}_{t}^{c}-\hat{\lambda}_{t}^{k}=-\frac{\xi_{k}}{2}\left(\hat{\imath}_{t}-\hat{\imath}_{t-1}\right)+\beta \xi_{k}\left(\hat{\imath}_{t+1}-\hat{\imath}_{t}\right)
$$

The first order condition with respect to $c_{t}$,

$$
\hat{\lambda}_{t}^{c}=-\frac{1}{\sigma} \hat{c}_{t}
$$

The first order condition with respect to bank capital, $e_{t}$, (with $\xi_{e}=0$, as used in the model).

$$
\hat{R}_{t}^{e}=\hat{R}_{t}^{d}+\frac{\Phi}{1-\Phi} \hat{\Phi}_{t}
$$

Wage Inflation,

$$
\hat{\pi}_{t}^{w}=\beta \mathbb{E}_{t} \hat{\pi}_{t+1}^{w}+\frac{\left(1-\omega_{w}\right)\left(1-\beta \omega_{w}\right)}{\left(\omega_{w}\right)\left(1+\eta \lambda_{w}\right)}\left[\widehat{m r s}_{t}-\hat{w}_{t}\right]
$$

Marginal rate of substitution,

$$
\widehat{m r s}_{t}=\eta \hat{n}_{t}+\frac{1}{\sigma} \hat{c}_{t}
$$

Real Wages,

$$
\hat{w}_{t} \equiv \hat{w}_{t-1}+\hat{\pi}_{t}^{W}-\hat{\pi}_{t}^{P}
$$

Utilized Capital,

$$
\widehat{\bar{k}}_{t}=\hat{u}_{t}+\hat{k}_{t-1}
$$

Inflation (NKPC),

$$
\hat{\pi}_{t}^{P}=\beta \mathbb{E}_{t} \hat{\pi}_{t+1}^{P}+\frac{\left(1-\omega_{p}\right)\left(1-\omega_{p} \beta\right)}{\omega_{p}} \widehat{m c}_{t}
$$

Marginal Costs,

$$
\widehat{m c}_{t}=\hat{\imath}_{t}^{l}+(1-\alpha) \hat{w}_{t}+\alpha \hat{r}_{t}^{k}-\hat{z}_{t}
$$

Loans,

$$
\hat{l}_{t}=\left[\frac{r^{k} \bar{k}}{l}\left(\hat{r}_{t}^{k}+\widehat{\bar{k}}_{t}\right)+\frac{w n}{l}\left(\hat{w}_{t}+\hat{n}_{t}\right)\right]
$$

Probability of default,

$$
\hat{\Phi}_{t}=\left(\frac{\varepsilon^{m}}{\varepsilon^{m}-\underline{\varepsilon}}\right) \hat{\varepsilon}_{t}^{m}
$$


Threshold point, $\varepsilon_{j, t}^{m}$.

$$
\hat{\varepsilon}_{t}^{m}=\hat{R}_{t}^{l}+\hat{l}_{t}-\hat{\chi}_{t}-\hat{a}_{t}-\alpha \widehat{\bar{k}}_{t}-(1-\alpha) \hat{n}_{t}
$$

Physical Capital-Labour ratio,

$$
\widehat{\bar{k}}_{t}-\hat{n}_{t}=\hat{w}_{t}-\hat{r}_{t}^{k}
$$

Deposit rate,

$$
R^{d} \hat{R}_{t}^{d}=(1-\mu) R^{c b} \hat{R}_{t}^{c b}-\left(R^{c b}-R^{\mu}\right) \mu \hat{\mu}_{t}+\mu R^{\mu} \hat{R}_{t}^{\mu}-G^{\mu} \hat{G}_{t}^{\mu}
$$

The adjustment equation for holding excess reserves,

$$
G^{\mu} \hat{G}_{t}^{\mu}=\left[\psi_{1}+\psi_{2}\left(\mu-\mu^{c b}\right)\right]\left(\mu \hat{\mu}_{t}-\mu^{c b} \hat{\mu}_{t}^{c b}\right)
$$

Total reserves,

$$
\mu \hat{\mu}_{t}-\mu^{c b} \hat{\mu}_{t}^{c b}=-\frac{1}{\psi_{2}}\left(R^{c b} \hat{R}_{t}^{c b}-R \hat{R}_{t}^{\mu}\right)
$$

Refinance Rate,

$$
\hat{R}_{t}^{c b}=\phi \hat{R}_{t-1}^{c b}+(1-\phi)\left[\phi_{y} \hat{y}_{t}+\phi_{\pi} \hat{\pi}_{t}^{P}+\phi_{l y} \hat{l}_{t}\right]+\epsilon_{t}^{i}
$$

Deposits,

$$
\hat{d}_{t}=\left(\frac{l}{l-e}\right) \hat{l}_{t}-\left(\frac{e}{l-e}\right) \hat{e}_{t}+\frac{\mu}{(1-\mu)} \hat{\mu}_{t}
$$

Equity (driven by regulation)

$$
\begin{aligned}
& \hat{e}_{t}=\hat{\gamma}_{t}^{r e g}+\hat{l}_{t} \\
& \hat{\gamma}_{t}=\hat{\gamma}_{t}^{r e g}+\epsilon_{t}^{\gamma}
\end{aligned}
$$

Goods Market Equilibrium Condition,

$$
y \hat{y}_{t}=g \hat{g}_{t}+c \hat{c}_{t}+i \hat{\imath}_{t}
$$

Taxes,

$$
\begin{aligned}
\tau \hat{\tau}_{t} & =g \hat{g}_{t}-\tau^{\mu} \hat{\tau}_{t}^{\mu}-\varphi_{0} \varphi_{\gamma} e\left[\hat{\gamma}_{t}^{r e g}-\hat{\gamma}_{t}\right] \\
\tau \hat{\tau}_{t} & =g \hat{g}_{t}-\tau^{\mu} \hat{\tau}_{t}^{\mu} .
\end{aligned}
$$

where the term $\tau^{\mu} \widehat{\tau_{t}^{\mu}}$ is determined from the seigniorage condition defined in the model, 
Loan Rate,

$$
\begin{aligned}
R^{l} \hat{R}_{t}^{l}= & (1-\gamma) R^{c b} \hat{R}_{t}^{c b}+\gamma R^{e} \hat{R}_{t}^{e}+\left(R^{e}-R^{c b}+\varphi_{0}\right) \gamma \hat{\gamma}_{t}+\varphi_{\gamma} \varphi_{0} \gamma\left(\hat{\gamma}_{t}^{r e g}-\hat{\gamma}_{t}\right)+ \\
& +\frac{\chi}{l / y}\left(\frac{\bar{\varepsilon}-\underline{\varepsilon}}{2}\right) \Phi^{2}\left(\hat{\epsilon}_{t}^{z}+\alpha \hat{k}_{t}+(1-\alpha) \hat{n}_{t}-\hat{l}_{t}+2 \hat{\Phi}_{t}\right) .
\end{aligned}
$$

Labour Demand (Production Function),

$$
\hat{n}_{t}=\frac{1}{1-\alpha} \hat{y}_{t}-\frac{\alpha}{1-\alpha} \hat{\bar{k}}_{t}-\lambda_{w}\left(\frac{\alpha}{1-\alpha}\right) \hat{r}_{t}^{k}-\lambda_{w}\left(\frac{1}{1-\alpha}\right) \hat{R}_{t}^{l}-\lambda_{w} \hat{w}_{t}+\left(\lambda_{w}-1\right)\left(\frac{1}{1-\alpha}\right) \hat{z}_{t} .
$$

\section{Efficient Economy Log-Linearization,}

First Best Euler Equation,

$\hat{c}_{t+1}^{*}=\hat{c}_{t}^{*}+\beta \sigma\left\{\alpha z u\left(\frac{n}{u k}\right)^{1-\alpha}\left[\hat{z}_{t+1}+\hat{u}_{t+1}^{*}+(1-\alpha)\left(\hat{n}_{t+1}^{*}-\hat{u}_{t+1}^{*}-\hat{k}_{t}^{*}\right)\right]-\delta_{0} u^{\delta_{1}}\left(\delta_{0} \delta_{1} \hat{u}_{t+1}^{*}\right)\right\}$.

Efficient Labour Supply,

$$
\hat{z}_{t}+\alpha\left(\hat{u}_{t}^{*}+\hat{k}_{t-1}^{*}-\hat{n}_{t}^{*}\right)=\eta \hat{n}_{t}^{*}+\frac{1}{\sigma} \hat{c}_{t}^{*}
$$

Capital Utilization,

$$
\hat{z}_{t}+(1-\alpha)\left(\hat{n}_{t}^{*}-\hat{u}_{t}^{*}-\hat{k}_{t-1}^{*}\right)=\left(\delta_{1}-1\right) \hat{u}_{t}^{*}
$$

Resource Constraint,

$$
\begin{aligned}
& z(u k)^{\alpha} n^{1-\alpha}\left[\hat{z}_{t}+\alpha\left(\hat{u}_{t}^{*}+\hat{k}_{t-1}^{*}\right)+(1-\alpha) \hat{n}_{t}^{*}\right] \\
= & c \hat{c}_{t}^{*}+k \hat{k}_{t}^{*}-k \hat{k}_{t-1}^{*}+\delta_{0} u^{\delta_{1}} k\left(\delta_{1} \hat{u}_{t}^{*}+\hat{k}_{t-1}^{*}\right)+g \hat{g}_{t} .
\end{aligned}
$$

Efficient Output,

$$
\hat{y}_{t}^{*}=\hat{z}_{t}+\alpha\left(\hat{u}_{t}^{*}+\hat{k}_{t-1}^{*}\right)+(1-\alpha) \hat{n}_{t}^{*}
$$

Output Gap,

$$
\hat{y}_{t}^{g a p}=\hat{y}_{t}-\hat{y}_{t}^{*}
$$

